\title{
Colonic Migrating Motor Complexes, High Amplitude Propagating Contractions, Neural Reflexes and the Importance of Neuronal and Mucosal Serotonin
}

\author{
Terence K Smith, ${ }^{1 *}$ Kyu Joo Park ${ }^{2}$ and Grant W Hennig ${ }^{1}$ \\ ${ }^{1}$ Department of Physiology and Cell Biology, University of Nevada School of Medicine, Reno, Nevada, USA; and ${ }^{2}$ Department of Surgery, School \\ of Medicine, Seoul National University, Seoul Korea
}

\begin{abstract}
The colonic migrating motor complex (CMMC) is a critical neurally mediated rhythmic propulsive contraction observed in the large intestine of many mammals. It seems to be equivalent to the high amplitude propagating contractions (HAPCs) in humans. This review focuses on the probable neural mechanisms involved in producing the CMMC or HAPC, their likely dependence on mucosal and neuronal serotonin and pacemaker insterstitial cells of Cajal networks and how intrinsic neural reflexes affect them. Discussed is the possibility that myenteric 5-hydroxytryptamine (5-HT) neurons are not only involved in tonic inhibition of the colon, but are also involved in generating the CMMC and modulation of the entire enteric nervous system, including coupling motility to secretion and blood flow. Mucosal 5-HT appears to be important for the initiation and effective propagation of CMMCs, although this mechanism is a longstanding controversy since the 1950s, which we will address. We argue that the slow apparent propagation of the CMMC/HAPC down the colon is unlikely to result from a slowly conducting wave front of neural activity, but more likely because of an interaction between ascending excitatory and descending (serotonergic) inhibitory neural pathways interacting both within the myenteric plexus and at the level of the muscle. That is, CMMC/HAPC propagation appears to be similar to esophageal peristalsis. The suppression of inhibitory (neuronal nitric oxide synthase) motor neurons and mucosal 5-HT release by an upregulation of prostaglandins has important implications in a number of gastrointestinal disorders, especially slow transit constipation.
\end{abstract}

(J Neurogastroenterol Motil 2014;20:423-446)

Key Words

5-HT neurons; Colon; Colonic Motor complex; Mucosa; Occult reflexes

Received: August 11, 2014 Revised: September 5, 2014 Accepted: September 8, 2014

(c) This is an Open Access article distributed under the terms of the Creative Commons Attribution Non-Commercial License (http://creativecommons. org/licenses/by-nc/3.0) which permits unrestricted non-commercial use, distribution, and reproduction in any medium, provided the original work is properly cited.

*Correspondence: Terence K Smith, PhD

Department of Physiology and Cell Biology, Anderson Medical Building/ms352, University of Nevada School of Medicine, Reno, NV 89557, USA

Tel: +1-775-784-4885, Fax: +1-775-784-6903, E-mail: tksmith@medicine.nevada.edu

Financial support: This study was funded by a grant from the National Institute of Diabetes and Digestive and Kidney Diseases (Grant No. P20 RR-1875).

Conflicts of interest: None.

Author contributions: Terence K Smith wrote the first draft of manuscript and constructed the figures; Kyu Joo Park and Grant W Hennig helped with calcium imaging experiments and reviewed the manuscript; Grant W Hennig critically reviewed the manuscript and made important suggestions concerning organization and figures.

ORCID: Terence K Smith, https://orcid.org/0000-0002-2120-2766. 


\section{Introduction}

In over 50 years of studying the enteric nervous system (ENS), the serotonergic system in the gastrointestinal (GI) tract is the one that has proved most reliable for therapeutic manipulation of motility and secretion. ${ }^{1-4}$ Serotonin (5-Hydroxytryptamine, 5-HT) is the most abundant signaling molecule in the gut that contains about $95 \%$ of the body's 5-HT. Its sources include mucosal enterochromaffin cells (EC cells, $>90 \%$ of 5-HT) and myenteric descending serotonergic neurons (about 2-5\%). ${ }^{5,6}$ The large number of different $5-\mathrm{HT}$ receptors in the gut (from $5-\mathrm{HT}_{1}$ to $5-\mathrm{HT}_{7}$ and its subtypes) amounts to about 14 different receptors that produce diverse effects on a wide range of targets. ${ }^{1,7}$ With the exception of $5-\mathrm{HT}_{3}$ receptors, which are ligand gated ion channels, the other receptors are coupled to $G$ proteins operating on different signaling pathways, several influencing the levels of cAMP in the target cell. ${ }^{1}$

Altered serotonergic signaling plays an important role in the pathophysiology of gastrointestinal disorders, including diarrhea induced by cholera toxin or bile salts and irritable bowel syndrome (IBS). ${ }^{2,8} 5-\mathrm{HT}_{3}$ receptor antagonists are effective against IBS with diarrhea, whereas, $5-\mathrm{HT}_{4}$ receptor agonists are effective against IBS with constipation. ${ }^{2,8}$ However, some drugs that target $5-\mathrm{HT}_{3}$ or $5-\mathrm{HT}_{4}$ receptors can potentially have adverse cardiovascular effects, as well as causing ischemic colitis $\left(5-\mathrm{HT}_{3}\right.$ antagonists and $5-\mathrm{HT}_{1}$ agonists), inhibiting the gastrocolic reflex (5- $\mathrm{HT}_{3}$ antagonists) and diarrhea (5- $\mathrm{HT}_{4}$ agonists). ${ }^{1,4,9}$

$5-\mathrm{HT}_{4}$ receptors are located on colonic epithelial cells, EC cells, goblet cells and enteric neurons. ${ }^{10,11}$ Fecal pellet propulsion along the isolated guinea-pig colon is more readily accelerated when $5-\mathrm{HT}$ or $5-\mathrm{HT}_{4}$ receptor agonists are applied intraluminally rather than serosally. ${ }^{10,12}$ Also, ascending contraction and descending relaxation of the circular muscle (CM) evoked by mucosal stimulation is inhibited by $5-\mathrm{HT}_{4}$ and $5-\mathrm{HT}_{1 \mathrm{p}}$ antagonists added to the stimulation site, suggesting that 5 -HT released by mucosal stimulation can initiate the peristaltic reflex by activating $5-\mathrm{HT}_{4} / 5-\mathrm{HT}_{1 \mathrm{p}}$ receptors on the mucosal endings of intrinsic primary afferent neurons (IPANs-Type 2/AH neurons) (Fig. 1). ${ }^{13}$ Alternative strategies include the possibility of using $5-\mathrm{HT}_{2 \mathrm{~B}}$ and $5-\mathrm{HT}_{7}$ receptors antagonists/agonists to treat GI disorders. ${ }^{3,9} 5-\mathrm{HT}_{2 \mathrm{~B}}$ receptors are located on a subset of myenteric neurons and interstitial cells of Cajal (ICC), ${ }^{14}$ whereas $5-\mathrm{HT}_{7}$ receptors are on IPANs ${ }^{15,16}$ and perhaps on the muscle. ${ }^{17}$
Despite the important role of 5-HT in gut pathophysiology, ${ }^{18}$ its role in normal colonic motility remains controversial. As will be addressed below, some studies suggesting that $5-\mathrm{HT}$ is critical while others suggest it is unimportant. ${ }^{8,19}$

Although myenteric 5-HT interneurons in the large intestine are relatively few, they have great divergence and probably act as a type of "central processing unit" in the colon influencing all levels of the ENS and pacemaker networks to coordinate motility with secretion and blood flow ${ }^{14}$ (Fig. 1). They also likely couple activities from several interconnected functional units, proximal colon (mixes viscous chyme), ${ }^{20}$ mid colon (produces fecal pellets), distal colon, rectum and internal anal sphincter (IAS). Both neuronal and mucosal 5-HT appear to coordinate stereotypical behaviors in the mammalian large bowel, including:

(1) Colonic migrating motor complexes $(\mathrm{CMMCs})^{8}$

(2) Tonic inhibition of the muscle ${ }^{21}$

(3) Secretomotor activity and blood flow ${ }^{14,22}$

CMMCs and high amplitude propagating contractions (HAPCs) are probably a similar integrated motor events (Fig. $2 \mathrm{~A}$ and $2 \mathrm{~B}$ ) normally involving both mucosal 5-HT and myenteric 5-HT neurons. These 2 types of 5-HT releasing cells are likely to be involved in the activation of IPANs (Fig. 1A and 3A). IPANs probably excite ascending excitatory and descending inhibitory nerve pathway that activate excitatory motor neurons (EMNs) and inhibitory motor neurons (IMNs) respectively, thereby altering smooth muscle contractility and modulating other cellular targets such as pacemaker activity. ${ }^{8,23-25}$ Some 5-HT neurons, which may also release acetylcholine (ACh), appear to be spontaneously active and contribute to tonic inhibition of the muscle and pacemaker ICC between CMMCs. ${ }^{21}$ 5-HT neurons are also necessary for CMMC propagation and generation. ${ }^{21}$ During the CMMC, there is a defined pattern switch that turns off IMNs to allow full excitation of the muscle and pacemaker ICC by EMNs. ${ }^{26-28}$

Without appreciating the integrated nature of the HAPC/ CMMC and the unified nature of the ENS there has been a tendency to focus on one or other of the individual components to explain changes in motility and secretion. ${ }^{29,30}$ An understanding of how motor and secretomotor activities are integrated and probably regulated by mucosal and neuronal 5 -HT will give insights into basic physiology of these important behaviors and also allow better targeting of different 5-HT receptors in GI disorders to normalize these interactions. ${ }^{22}$ 
A

Potential neural pathways in the colon

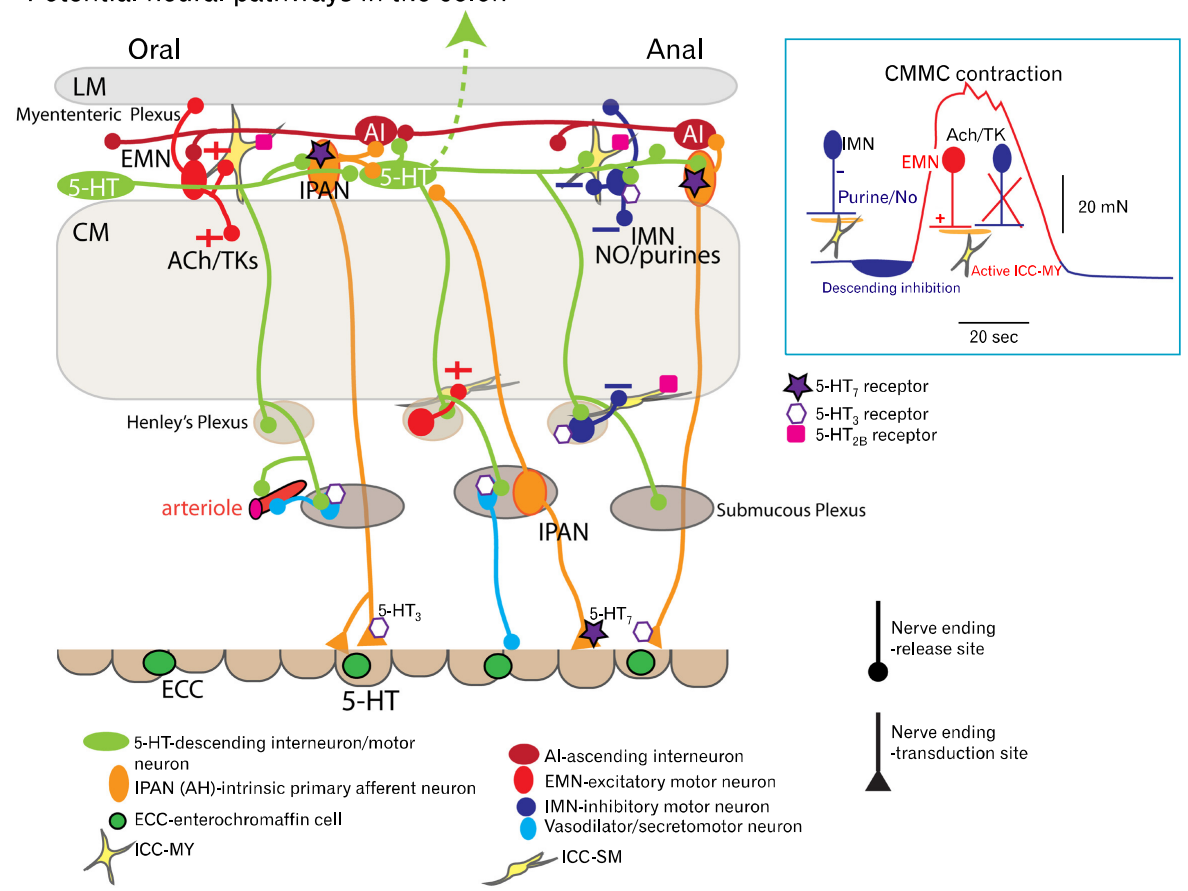

B

A myenteric 5-HT neuron

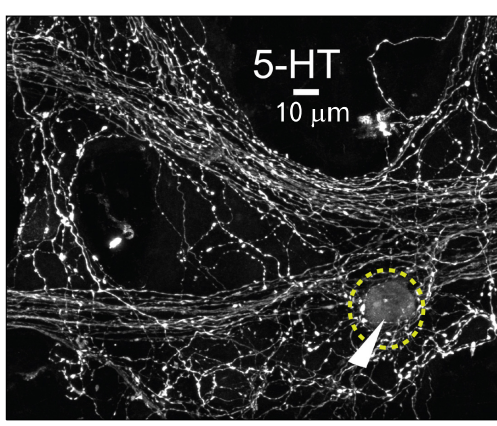

C

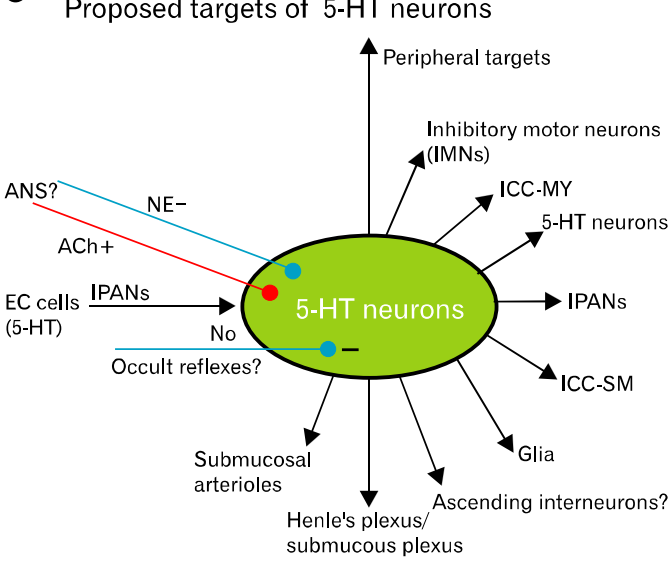

Figure 1. Possible projections of myenteric 5-hydroxytryptamins (5-HT) neurons. (A) Schematic illustration of the proposed nerve pathways activated by a myenteric 5-HT neuron(s) (green), which connect to all levels of the ENS and pacemaker networks, as well as some of their major serotonergic receptors. Mucosal 5-HT in enterochromaffin cells (ECC) activate intrinsic primary afferent neurons (IPANs; orange), which in turn can excite myenteric 5-HT neurons that synapse with both inhibitory motor neurons (IMNs; blue) and IPANs, which synapse with ascending interneurons (AI; red) that activate excitatory motor neurons (EMNs; red) to excite pacemaker myenteric interstitial cells of Cajal (ICC-MY; yellow) and muscle. The $5-\mathrm{HT}_{7}$ receptor, but not the $5-\mathrm{HT}_{1 \mathrm{P}}$ receptor, is shown on IPANs because they are possibly the same receptor. Insert shows the motor neurons operating during different phases of the CMMC. Between CMMCs IMNs are active and produce tonic inhibition. Their activity increases just prior to the CMMC to generate descending inhibition, necessary for effective propagation of the CMMC. To help create the CMMC contraction, IMNs switch off and EMNs, which release acetylcholine (ACh) and tachykinins (TK), are activated. (B) A 5-HT neuron cell body (arrow) and varicose nerve fibers in the myenteric plexus of the murine colon. (C) Schematic illustration of the extensive projections of 5-HT neurons, which may be inhibited by occult reflexes and receive sympathetic and parasympathetic inputs from the autonomic nervous system. 


\section{Importance of 5-hydroxytryptamine Neurons in the Gastrointestinal Tract}

\section{Myenteric Serotonergic Neurons}

The role of mucosal 5-HT has been reviewed ${ }^{5,6,8,31,32}$ so in this section we will focus on our current knowledge of 5-HT neurons in the GI tract, since their role in motility is often under appreciated. ${ }^{5}$ 5-HT neurons, along with their numerous 5-HT receptors, are found in the myenteric plexus of every region of the GI tract from small rodents to humans, ${ }^{11,14,33}$ suggesting that 5-HT is an important and conserved neurotransmitter. ${ }^{7}$ 5-HT neurons are those neurons that synthesize serotonin from tryptophan hydroxylase $(\mathrm{TPH})$, which is the rate limiting enzyme in the synthesis of 5-HT from the amino acid L-tryptophan. ${ }^{5,32,34}$ $\mathrm{TPH} 2$ is found in brain and myenteric neurons whereas TPH1 is specific to EC cells. Genetic deletion of TPH1 (TPH1 knockout [KO] mice) reduces $5-\mathrm{HT}$ in the gut to about $2 \%$ of control because it eliminates mucosal 5-HT, but does not alter 5-HT levels in the brain. In contrast, genetic deletion of TPH2 (TPH2 $\mathrm{KO}$ mice) virtually eliminates 5 -HT in the brain, but hardly alters the total 5-HT content of the gut, because the EC cell pool of 5 -HT is much in excess of that in myenteric neurons. ${ }^{32,35}$

Most immunohistochemical studies have used serotonin loading of tissue to enhance 5-HT neuron visibility. ${ }^{14,33,36,37}$ Other amine handling neurons maybe inadvertently labeled that do not synthesize 5-HT but take up 5-HT. ${ }^{33,36}$ Given this caveat, myectomy studies combined with immunohistochemistry have observed that 5-HT neurons, which occur only in the myenteric plexus, have a predominantly anal projections (up to $17 \mathrm{~mm}$ in the guinea-pig distal colon ${ }^{38}$ ), suggesting they are descending interneurons that project down the gut and synapse with one another forming chains of interconnected Dogiel Type I/S interneurons (Fig. 1A and 1B). ${ }^{14,33,39}$ However 5-HT neurons are often surrounded by a dense neuropil of serotonergic fibers often making it difficult to determine whether they are truly uniaxonal neurons, neurons with many collaterals, or even perhaps multipolar neurons, as observed in the murine, porcine and human colon (Fig. 1B)..$^{14,40,41}$

5-HT neurons, like IPANs, are fairly large neurons that are also calbindin positive and cholinergic neurons. ${ }^{14,39}$ However, less than one-third of serotonergic nerve varicosities (sites of transmitter release) contain the vesicular ACh transporter ${ }^{42}$ suggesting that although $5-\mathrm{HT}$ is a primary neurotransmitter some varicosities may release $\mathrm{ACh}$ and uptake choline.

5-HT neurons are some of the longest neurons in the gut since they also have extensive projections outside the bowel. They can also be considered as intestinofugal neurons as they project out of the gut to innervate the pancreas, mesenteric arteries and prevertebral ganglia. ${ }^{43-45}$ 5-HT pathways in the CNS do not project to the gut - and the sources of 5-HT endings in the gut and these other organs are, in fact, all from enteric 5-HT neurons (Fig. 1C).

The importance of 5-HT neurons in controlling gut motility is underscored by the fact that they appear to be directly targeted by extrinsic nerves of the autonomic nervous system (ANS). In the small intestine, 5-HT neurons appear to be targeted by sympathetic nerves since they are preferentially surrounded by baskets of tyrosine hydroxylase terminals, ${ }^{46}$ suggesting that norepinephrine (NE) could potentially reduce activity in these particular neurons. Sympathetic nerve stimulation inhibits both spontaneous and evoked CMMCs in the isolated murine and guinea-pig colon. ${ }^{35,47}$ As mentioned, myenteric 5-HT neurons appear to innervate sympathetic neurons in prevertebral ganglia, ${ }^{44}$ suggesting they could also act as intestinofugal neurons. In the stomach vagal stimulation appears to activate myenteric 5-HT neurons that synapse with IMNs to produce receptive relaxation of the stomach. ${ }^{48}$

Genetic deletion of TPH2 accelerates gastric emptying (no activation of IMNs by 5-HT neurons) and dramatically slows intestinal transit and the ejection of a bead from the rectum, possibly because overall numbers of enteric neurons and other cell types are reduced in TPH2 $\mathrm{KO}$ mice. 5-HT neurons are important precursors in the development of a number enteric neurons, ICC and the mucosa. ${ }^{32,34}$ In contrast, genetic deletion of TPH1 does not appear to affect total GI transit time implying that mucosal $5-\mathrm{HT}$ is unnecessary for constitutive motility. ${ }^{34}$ However, we have recently shown that propulsion along the isolated TPH1 KO mouse colon is significantly affected by a lack of mucosal 5-HT, suggesting there are compensatory changes that appear to restore transit (see below). ${ }^{8}$ Inflammation is more severe in TPH2 $\mathrm{KO}$ mice than in TPH1 KO mice, since neuronal 5-HT shields enteric neurons from inflammatory damage. ${ }^{5}$

\section{Diverse Projections of Serotonergic Neurons in the Colon}

The differential amounts of 5-HT in the mucosa and neurons in the gut may create the impression that neuronal $5-\mathrm{HT}$ is relatively unimportant, although, as pointed out by Professor 
Gershon (2012), "...the size of a package does not necessarily determine its importance." For instance, the giant cerebral serotonergic neuron in Aplysia (sea slug) synapses with many different post synaptic targets including glial cells, other neurons, muscle, gut and glands to mediate a number of behaviors including arousal and feeding. ${ }^{49}$ In fact, serotonergic neurons coordinate or modulate firing in neural networks that mediate motor behaviors in many invertebrates. ${ }^{50-52}$ These include swimming in the leech, escape reflexes in crustaceans, as well as pyloric motor patterns generated by gastric mill neurons in crabs.

Similarly, 5-HT immunohistochemistry, without the usual 5-HT preloading, has revealed myenteric serotonergic cell bodies in the murine colon ( $<1$ every 3 ganglia; Fig. 1B) in the proximal to mid colon and even fewer in the distal colon a diverse array of targets. ${ }^{14}$ They have extensive projections throughout the ENS, as well as pacemaker ICC and intramuscular ICC (Fig. 1). 5-HT axons originating from their few cell bodies must be extremely divergent since they form a dense varicose network throughout myenteric plexus, even in ganglionated regions that do not contain 5-HT cell bodies (Fig. 1B and 1C). ${ }^{14} 5$-HT neurons appear to synapse with one another, other interneurons, nearly all myenteric neuronal nitric oxide synthase (nNOS) positive IMNs and interneurons (ratio of 5-HT neurons to nNOS neurons - 1:15), IPANs, glial cells, intramuscular ICC (which are intermediaries in neurotransmission) and also appear to make varicose contacts with pacemaker myenteric ICC (ICC-MY) and submucosal ICC (ICC-SM). ${ }^{14}$ Whether each myenteric 5-HT neuron projects to multiple targets throughout the gut wall has not been quantified, although this possibility exists as there are a relatively small number of these neurons. Myenteric 5-HT nerve axons appear to innervate the submucosal pacemaker network (ICC-SM) and nNOS neurons in Henle's plexus (perimuscular ganglia), which regulate slow wave activity generated by ICC-SM, ${ }^{53}$ and submucosal neurons. ${ }^{14}$

Myenteric 5-HT axons also run along the adventitial surface of submucosal arterioles, suggesting that serotonin can directly constrict arteries as well as indirectly stimulating vasodilator neurons in submucosal ganglia. ${ }^{14,22}$ How the direct release of 5-HT in blood vessels coordinates with the output of vasodilator neurons in the submucosal plexus has not been determined. Blocking $5-\mathrm{HT}_{3}$ receptors can lead to ischemic colitis; ${ }^{4}$ this could be explained by reduced vasodilator output from submucosal neurons leading to constriction of submucosal arteries. Therefore, myenteric serotonergic neurons are not just interneurons as commonly believed but also could be described as "motor" neurons to ICC and arteries.

Importantly, if myenteric 5-HT neurons are essential for generating not only tonic inhibition of the colon but also the CMMC then presumably they should be spontaneously active and lead firing in most myenteric neurons, as they appear to do (Fig. 3A).The concept that a few neurons can dramatically change the behavior in an entire network or organism has been borne out by many invertebrate studies. ${ }^{50}$ We suggest that $5-\mathrm{HT}$ neurons, while few in number, may have a disproportionally greater influence on GI motility than other classes of neurons due to the dense innervation of such a diverse range of cells in the gut wall. In this sense, 5-HT neurons are likely to be a command neuron or an important modulator of command neurons, a familiar concept in invertebrate neurobiology. ${ }^{54,55} \mathrm{~A}$ command neuron is a single neuron or a small group of neurons than can initiate complex motor behaviors.

\section{Propagating Neurally Mediated Contractions in the Colon}

\section{Equivalence of Colonic Migrating Motor Complexes and High Amplitude Propagating Contractions}

We propose that the basic physiology of colonic contractions (CMMCs and HAPCs) is conserved among animals and humans as are the basic mechanisms of peristaltic contractions in the esophagus. $^{56}$

Before we discuss the role and controversies surrounding mucosal and neuronal 5-HT, we would like to draw some similarities between neurally mediated propagating contractions in the large bowel that have been observed in a variety of mammals from small rodents to humans (Fig. 2). Although these propagating contractions have been given a variety of names such as CMMCs, giant migrating contractions, giant contractions, myoelectric complexes, migrating spike bursts, peristaltic contractions, HAPCs and propagating pressure sequences, ${ }^{8,57-71}$ they are probably generated by similar mechanisms (Fig. 2 and 3).

Manometric studies of the human colon of adults and children have recorded a series of neurally mediated HAPCs that can propel fecal matter and give rise to an urge to defecate. ${ }^{62,63}$ HAPCs are rare events (about 7 per 24 hours in humans), but usually occur in bursts following feeding (gastrocolic reflex) or upon waking (Fig. 2B). ${ }^{63,72}$ Their rarity may be due to myenteric neurons being normally inhibited by sympathetic nervous activ- 
A

CMMCs isolated murine colon

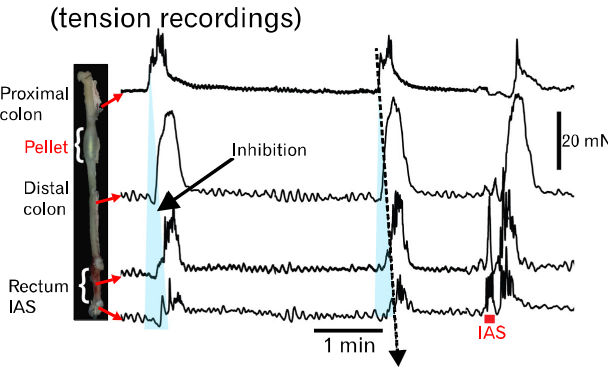

B

HAPCs in the adult human colon (manometric recordings)

C

HAPCs in an isolated segment of human sigmoid colon (tension recordings)

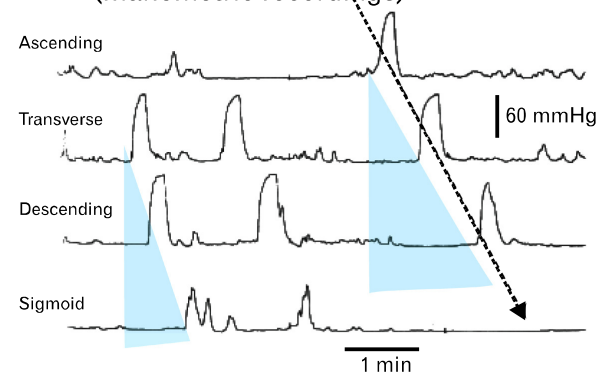

Hexamethonium (100

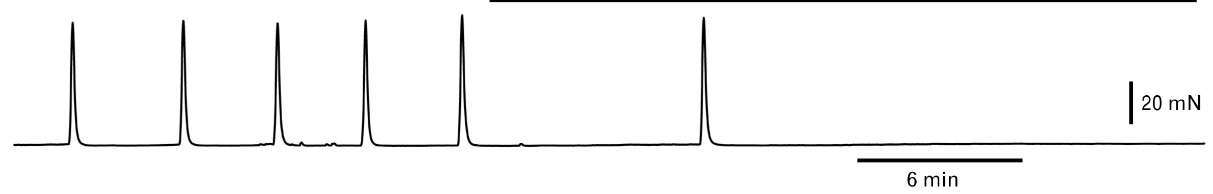

D Spontaneous CMMC in CM from control and POM-STC mouse colon (intracellular electrical recording from $\mathrm{CM}$ )

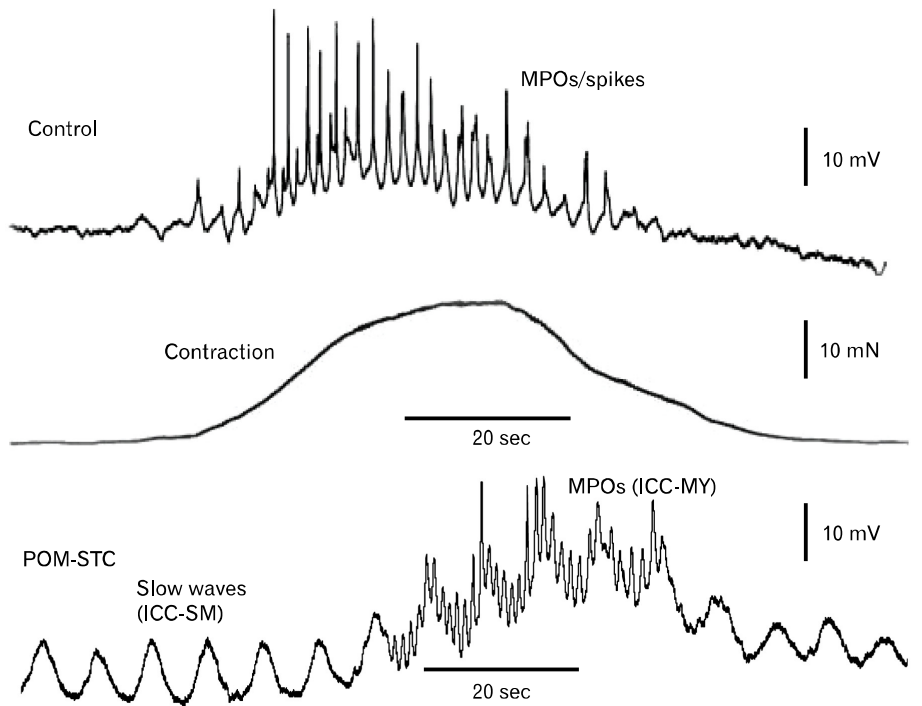

Figure 2. Comparison of colonic migrating motor complexs (CMMCs) and high-amplitude propagating contractions (HAPCs). (A) When a fecal pellet is held in the isolated murine colon spontaneous $\mathrm{CMMCs}$ propagate down the colon and there is a brief relaxation of the rectum and internal anal sphincter (IAS), which is followed by a rebound contraction. Mucosal stimulation of the IAS/rectum with an artists brush, elicits a premature CMMC that propagated towards the proximal colon (last trace). (B) HAPCs in the human colon in vivo recorded upon awakening have a frequency and duration similar to those observed in the mouse colon (adapted from Bassotti and Gaburri ${ }^{62}$ with permission). Blue triangles represent inhibition preceding CMMCs. (C) Spontaneous CMMCs/HAPCs in an opened pinned segment (6 cm long) of isolated sigmoid colon from a cancer patient that were blocked by hexamethonium (nicotinic antagonist) (recorded by Dr Sang Don Koh and Robert Corrigan; tissue provided by Dr Kent Sasse, Renown Hospital, Reno, NV). (D) Spontaneous CMMC (plus associated contraction) in control and partially obstructed slow transit constipation (POM-STC) recorded with intracellular microelectrodes from a circular muscle (CM) cell in the isolated mouse colon. Note the fast oscillations superimposed on a slow depolarization and prominent slow wave activity in the POM-STC mouse (recorded by Dr Dante Heredia). MPOs, myenteric potential oscillations.

ity ${ }^{63,73-75}$ or the intrinsic occult inhibitory neural reflex. ${ }^{69,76,77}$ The occult inhibitory reflex is triggered by colonic elongation caused by the accumulation of fecal matter. ${ }^{69,76}$ Colonic elongation acti- vates mainly long descending mechanosensitive nNOS positive sensory interneurons that are triggered by longitudinal stretch. These particular interneurons release nitric oxide (NO) to depress 
myenteric neurons underlying the CMMC and peristalsis. ${ }^{69,76,77}$

Blocking NO synthesis in healthy humans increases the number of propagating contractions. ${ }^{68}$ Furthermore, flushing the human colon increases the number of HAPCs. ${ }^{78,79}$

HAPCs can be activated by parasympathetic nerve activity during the gastrocolic reflex and by distension. ${ }^{63}$ The gastrocolic reflex in the large bowel maybe somewhat equivalent to the swallow induced peristaltic wave in the esophagus. ${ }^{6}$ When HAPCs occur following the gastrocolic reflex or upon waking they have a similar duration and frequency to CMMCs observed in the isolated colon of mice (Fig. 2A and 2B). ${ }^{62,63}$ They propagate down the colon at a velocity of about $0.2-12 \mathrm{~cm} / \mathrm{sec}^{62,63}$ A faster conduction velocity implies shorter latency between propagating HAPCs measured at several points along the colon (Fig. 2A and 2B). ${ }^{7}$

As HAPCs propagate down the colon they appear to be immediately preceded by an inhibitory or relaxation phase, ${ }^{80}$ although this relaxation phase is not always obvious in manometric recordings (see blue triangles in Fig. $2 \mathrm{~A}$ and $2 \mathrm{~B}$ ). ${ }^{62}$ This inhibitory phase appears to be essential for the oral to anal propagation of HAPCs, as it is for CMMCs and pellet propagation in mice (Fig. 2A and 2B) $)^{8,24,81}$ and peristaltic contractions in the esophagus (compare Fig. 2B above with Fig. 1 in Goyal and Chaudhury ${ }^{56}$ ). The increased propagation delay between HAPCs in the human colon in vivo compared to that in the isolated human and murine colon maybe due to the activation of parasympathetic nerves that excite IMNs during the gastrocolic reflex. Several mechanisms have been proposed for this delay, some of which are similar to those postulated for the esophagus, ${ }^{56}$ as discussed in "Do colonic migrating motor complexes/high amplitude propagating contractions really propagate?" section.

The development of high resolution manometry reveals that there is a motor pattern, termed propagating pressure sequences (PPSs), in the large bowel that is difficult to resolve with standard manometry. ${ }^{82-84}$ PPSs can originate in different parts of the colon and propagate over varying distances, although some in the normal colon propagate throughout the colon in an oral to anal direction and often have a similar duration to CMMCs. Those PPSs that originate near the rectum, and propagate orally, likely retard the flow of fecal material.

\section{Colonic Migrating Motor Complexes in the Isolated Human Colon}

When HAPCs occur in the human colon in vivo they are remarkably similar in frequency and duration to CMMCs in the isolated colon of mice (Fig. 2A and 2B). Moreover, in the iso- lated empty human colon, which does not have functional extrinsic inputs, colonic contractions (referred to as CMMCs) have been observed to occur at a similar frequency and duration to those in the isolated murine colon (Fig. 2C) and are similarly coordinated over long lengths of the large intestine. ${ }^{71,85}$ Moreover, intraluminal distension initiates a premature CMMC that is also preceded by a brief relaxation phase, i.e., distension activates descending inhibitory and ascending excitatory nerve pathways. ${ }^{71,85}$

However, the delay between CMMCs measured at different points down the empty isolated human colon appears to be considerably shorter than those observed in vivo (Fig. 2B), ${ }^{71,85}$ suggesting: (1) because the isolated colons were empty descending inhibition was not effectively activated by colonic content. In fact, CMMCs observed in the isolated human colon appear to propagate in both an oral or anal direction, (2) mucosal release of 5-HT could have been compromised because of hypoxic conditions within the colonic tube because the lumen does not appear to have been perfused and (3) activation of parasympathetic nerves in vivo is necessary for strong activation of IMNs, as it appears to be in the esophagus. ${ }^{56}$

\section{High Amplitude Propagating Contractions, Slow Transit Constipation and 5-hydroxytryptamine}

Some form of functional outlet obstruction has been reported in about $50 \%$ of patients with slow transit constipation (STC) ${ }^{86-88}$ One form of outlet obstruction is the inability of the puborectalis muscle to relax, which is necessary to allow the colon to straighten for effective defecation. ${ }^{89,90}$ Also an elongated (redundant or dolichocolon) colon has been linked to patients with STC, as well as strong phasic contractions linked to slow wave activity, and an excessive production of NO. ${ }^{81}$ "The most common related cause of constipation after ARM (anorectalmyectomy) was a redundant colon," ${ }^{88}$ which is also observed with barium enema X-ray studies in patients with STC. ${ }^{81}$ Elongated colons were at times surgically shortened; however, this method of treatment was not successful ${ }^{81}$ since the occult reflex is likely still present in the remaining colon.

Manometric studies in adults have reported fewer HAPCs in STC. ${ }^{63,91}$ One possibility is that the impacted and hence more elongated colon strongly activates the occult reflex that releases NO to reduce the amplitude and frequencies of HAPCs. ${ }^{92}$

Colonic motility in a mouse model of STC generated by a partial outlet obstruction (partially obstructed STC mouse [POM-STC]) applied to the anal outlet but not to the gut itself 
revealed similarities that were observed in some forms of human STC ${ }^{81}$ POM-STC mice exhibited: (1) reduced fecal pellet output; (2) muscle hypertrophy; (3) an elongated impacted large bowel with larger fecal pellets; (4) a depression of colonic motility in the impacted colon due to excessive amounts of NO production; (5) an intact occult inhibitory reflex; (6) slow transit of fecal pellets along the empty colon; (7) CMMCs that occurred synchronously along the empty colon due to a suppression of the descending inhibitory nerve pathway; (8) pronounced slow-wave activity due to a lack of tonic inhibition; (9) CMMCs in preparations without the mucosa; and (10) importantly, no mucosal reflexes. Figure 2D shows a control CMMC and a CMMC in the POM-STC mouse colon, which lacks tonic inhibition but has prominent slow wave activity.

The hyper-excitability of the POM-STC colon was largely due to suppression of only descending inhibitory nerve pathways by prostaglandins. ${ }^{81}$ Most of these changes appeared to be attributed increased cyclooxygenase (COX-2) levels in myenteric glia and the mucosa, since a COX-2 inhibitor, or removal of the obstruction for 1 week, restored the inhibitory nerve pathways and propagating CMMCs as well as mucosal reflexes. ${ }^{81}$

As there were still CMMCs in the POM-STC mice it is likely that PGE2 was suppressing IMNs but not 5-HT neurons, which are involved in generating CMMCs. ${ }^{21}$ The phenomena observed in POM-STC mice were somewhat similar to those observed in the TPH1 KO mouse colon that lacks mucosal 5-HT. ${ }^{8}$

In the isolated human colon from colectomy patients with STC, CMMCs (HAPCs) occurred at a similar frequency and duration as those in mice, but appeared to occur synchronously rather than propagating over long lengths of colon. ${ }^{71,85}$ Furthermore, there were a number of spurious contractions between their CMMCs in colons from patients with STC, ${ }^{71}$ suggesting that tonic inhibition might be compromised. Importantly intraluminal distension evoked a premature CMMC but not the preceding inhibitory response, ${ }^{85}$ suggesting that in these colectomy patients with STC, as in the POM-STC mice, the ascending excitatory nerve pathways are intact, but the descending inhibitory nerve pathways appear to be suppressed.

As CMMCs can still occur in these patients, it is likely that 5-HT neurons, IPANs and most enteric neurons and pacemaker ICC are still functional but only the descending inhibitory nerve pathways are suppressed in STC. Mucosal release of 5-HT may also be compromised because of upregulation of COX-2, as observed in the POM-STC mice. Abnormal levels of prostaglandin and COX enzymes have been observed in female patients with
STC. ${ }^{93}$ Therefore, in many cases colectomy appears to be a heavy-handed way to resolve STC.

In contrast, diarrhea and IBS can be associated with an increase in HAPCs that may contribute to abdominal pain., ${ }^{9,63}$

\section{Properties of Rhythmic Propagating Colonic Migrating Motor Complexes in Mice}

Most of what we know about the possible involvement of 5-HT and the intricate mechanisms and underlying the generation and propagation of motor complexes in the large bowel largely come from studies in the isolated murine colon, ${ }^{21,25,64-66,94,95}$ although earlier studies in the feline and canine colon have contributed significantly to our understanding. ${ }^{59,60,67}$ There appear to be notable similarities between HAPCs in the human colon and propagating motor complexes observed in the other species, especially those in mice (Fig. 2A-C). The mouse large intestine is a useful model for studying many aspects of human colonic motility and secretion with the proviso that "essentially, all models are wrong, but some are useful" -George E P Box (statistician). Furthermore, the whole murine colon is easily dissected from the animal and a minimum of effort is required to mount the whole colon in an organ bath. Also, the isolated colon, which readily generates spontaneous CMMCs, can be kept alive for hours with appropriate oxygenation. ${ }^{8,24,26,28}$ The size of the mouse means that the whole intestine can be studied readily in vivo, ${ }^{96}$ whereas in other animals the colon is usually, but not always, ${ }^{7}$ studied as isolated segments (Fig. 2C). ${ }^{19,97}$

However, we believe that the study of CMMCs in mice will more readily give insights into the mechanisms underlying the HAPC in humans and help direct research into this most important propulsive motor behavior.

The generation of the CMMC is dependent upon the ENS, but not the CNS, since they occur in isolated colons devoid of functional extrinsic inputs and are often rhythmic (Fig. 2C). ${ }^{24,65,94}$ In the murine colon CMMCs contractions occur approximately every 2 to 4 minutes and have a duration of about 40-60 seconds. ${ }^{65}$ Hexamethonium blocks the CMMC, demonstrating nicotinic cholinergic neurotransmission between enteric neurons is essential for their generation, as it appears to be in humans (Fig. 2C). ${ }^{24}$ However, the CNS/ANS can certainly initiate complexes, as in the gastrocolic reflex, where parasympathetic nerves raise the excitability of myenteric neurons to produce a burst of HAPCs.

The first phase of the CMMC consists of a relaxation (inhibitory phase), which determines its direction of propagation, followed by a second phase consisting of a strong contraction re- 
sulting mainly from activation of EMNs and perhaps by rebound contraction following the activation of IMNs, which is clearly seen in the IAS (Fig. 2A). ${ }^{8,24}$ CMMCs exert considerable force on a fixed pellet, ${ }^{24}$ which will propagate down the colon if it is free to move; if not, the CMMCs will propagate over the pellet. Between CMMCs the contractile activity is reduced because of tonic inhibitory drive to the CM and pacemaker ICC, which inhibits slow waves and related motor activities (Fig. 2C and $3 \mathrm{~B}) .^{21,25,28,81}$ However, tonic inhibition does not appear to contribute significantly to the rhythm of CMMCs since their frequency is similar to control in the nNOS KO mouse, POMSTC mouse and TPH1 KO mouse. ${ }^{8,25,81}$

CMMCs normally originate in the cecum/proximal colon (right or ascending colon in humans), and usually propagate anally, possibly because 5-HT neurons appear to be densest in this region. ${ }^{14}$ In contrast, EC cells appear to have a fairly uniform distribution along the colon. ${ }^{98}$ The direction of propagation of CMMCs is particularly entrained when a fecal pellet, which releases 5-HT from the mucosa that activates IPANs, is held in position in the isolated mouse colon, leading to regular oral to anal propagation of CMMCs down the entire length of the colon into the rectum and IAS, where they appear to generate a relaxation followed by a rebound contraction (Fig. 2A). ${ }^{8,24,99}$ Under these circumstances the CMMC behaves like a rhythmic peristaltic wave since it involves activation of myenteric descending inhibitory and ascending excitatory nerve pathways.

Furthermore, if a fecal pellet is held in the lumen of the isolated guinea-pig distal colon, which rarely exhibits spontaneous CMMCs, ${ }^{100}$ then rhythmic orthogradely propagating CMMCs are observed. ${ }^{101}$ Paralyzing the muscle with atropine or nicardipine around the pellet blocked these evoked CMMCs suggesting that muscle tone was important in their generation, likely because IPANS are not only activated by mucosal inputs but also sense muscle tension, i.e., they are polymodal sensory neurons. ${ }^{26,31,102}$ This also suggests that the colon is always attempting to move fecal matter down the bowel, unless inhibited by other factors such as sympathetic tone and occult reflexes. ${ }^{35,47,77}$

CMMCs can be recorded at the extreme oral end but not within about $10 \mathrm{~mm}$ of the anal end in a colonic sheet preparation, ${ }^{103}$ suggesting that ascending interneurons can also be activated by descending nerve pathways. ${ }^{25,103}$ In addition, the pattern of activity in enteric neurons involved in generating CMMCs appears quite well-preserved, even if mucosal stimulation to evoke a CMMC is applied to either end of the colon, also suggesting a convergence of ascending and descending interneurons onto the same myenteric neurons. ${ }^{26,70,103,104}$

Fairly long segments of colon are necessary for generating CMMCs since sectioning the murine colon to less than about 10 $\mathrm{mm}$ in length abolishes the CMMC activity in the mouse. ${ }^{66}$ This implies that a significant portion of functioning myenteric plexus is required for the generation of the CMMC, i.e., not only IPANs but also ascending interneurons. ${ }^{103}$

The site and properties of the cells necessary for generating CMMCs are unclear, but likely involve interactions between EC cells, enteric neurons, glia and pacemaker ICC. ${ }^{8,24,26,28,105}$

\section{Do Colonic Migrating Motor Complexes/High Amplitude Propagating Contractions Really Propagate?}

The apparent slow conduction velocity of CMMCs is similar to the velocity of a moving fecal pellet (about $0.8 \mathrm{~mm} / \mathrm{sec}$ mouse). ${ }^{24}$ How the CMMC propagates along the colon is unclear, although there are several possible scenarios. If a turning off of tonic inhibition (disinhibition) is the mechanism underling the rhythmic migrating spike burst in the isolated cat colon ${ }^{64}$ it is hard to envisage how disinhibition or a turning off of IMNs would propagate as a contraction along the colon. Others have suggested that a slowly conducting wave front of neural activity through the myenteric plexus is responsible for the slow migration of a motor complex. ${ }^{66,106}$ Indeed, computer modeling of a migrating motor complex in the small intestine envisages that it is recurrent synaptic connections between myenteric IPANs that excite each other via slow excitatory postsynaptic potentials (sEPSPs), which determine the duration of the complex, together with negative feedback produces a slowly propagating wave front of neural activity through the network of IPANs. ${ }^{106}$ However, at that time the possible role of serotonergic neuronal pathways or the mucosa was not considered. IPANs in the colon do indeed appear to be activated just before the CMMC contraction (Fig. 3A), although so far we have not observed this slow conduction of the CMMC though the myenteric plexus, ${ }^{26}$ possibly because the conduction along myenteric axons is much faster $(100-300 \mathrm{~mm} / \mathrm{sec})^{107}$ than the apparent conduction velocity of the CMMC. With such fast neurotransmission through the myenteric plexus, one could expect much of the colon to be excited at the same time.

The CMMC contraction usually has a fairly constant duration as it propagates down the colon, whereas the delay (inhibition) between successive CMMC/HAPCs increases with distance down the colon, similar to that occurring during esophageal 
peristalsis induced by a swallow (Fig. $2 \mathrm{~A}$ and $2 \mathrm{~B}$ ). ${ }^{56}$ Descending inhibition maybe just as important as contraction for propelling colonic contents, particularly solid boluses, since it determines the propagation velocity of the CMMC (see Fig. 2B).

After blocking $\mathrm{NO}$ synthesis with $\mathrm{N} \omega$-nitro-l-arginine (L-NA) CMMCs not only increase in frequency but also appear to occur almost synchronously along the colon, ${ }^{25,69}$ suggesting that NO is important in their conduction along the colon. Similarly, peristaltic contractions in the esophagus also occur almost synchronously after blocking NO. ${ }^{108}$ This leads to the possibility that the delay of the CMMC down the colon is largely dependent on descending serotonergic inhibitory nerve pathways that by releasing NO from nNOS motor neurons (or nNOS interneurons) could suppress activity in IPANs and other cholinergic neurons in ascending excitatory nerve pathways (Fig. 1A). ${ }^{64,105,109}$ In addition, much of the delay before the CMMC/ HAPC could also be produced at the level of neurotransmission to the muscle, as appears to be the case for the esophagus. ${ }^{56}$ Myenteric glia, which may also be activated by 5-HT neurons, ${ }^{14}$ could also be a contributing factor since by possibly releasing NO or prostaglandins they may also suppress activity in myenteric neurons; as they appear to do during the CMMC. ${ }^{105}$

During the initial phase of the CMMC, IMNs and EMNs are probably activated almost simultaneously. ${ }^{26}$ The conductances activated by inhibitory and excitatory neurotransmitters could be summating at the level of the muscle with inhibitory neurotransmitters delaying the onset of the excitatory contractile response (Fig. 1, Insert). In fact, IMNs turn off during the CMMC to allow full excitation of the muscle and pacemaker ICC. ${ }^{26,28}$ Therefore, if not for the preceding inhibitory response in the muscle, which appears to be dependent largely on NO in the proximal colon and purines (acting through $\mathrm{P} 2 \mathrm{Y}$ receptors) in the distal colon ${ }^{110}$ we would also expect CMMCs to occur almost synchronously along the colon. NO appears to act through intramuscular ICC and purines through platelet-derived growth factor receptor $\alpha$-positive (PDGFR $\alpha^{+}$) cells within the smooth muscle syncytium; both neurotransmitters producing inhibition of the muscle. ${ }^{111}$

In fact, in the $\mathrm{P} 2 \mathrm{Y} 1$ receptor $\mathrm{KO}$ isolated mouse, pellets propagate along the isolated proximal colon but not along the distal colon where purinergic neurotransmission to the muscle is absent. ${ }^{110}$ Also, in these mice CMMCs propagate along the proximal colon, but occur synchronously along the distal colon (Koh, Ward, Sanders and Smith, unpublished observations), suggesting the mechanism for delaying the CMMC is absent.
Furthermore, in support of the muscle hypothesis, CMMCs occur synchronously: (1) after ondansetron, which inhibits/blocks descending inhibition, ${ }^{8,22}$ (2) in POM-STC mouse where descending inhibitory nerve pathways and mucosal release of 5-HT is inhibited by prostaglandins (upregulation of COX-2), ${ }^{81}$ (3) in THP1 KO mouse colon that has compromised descending inhibition because of a lack of mucosal 5-HT and (4) in human isolated colon from colectomized patients with STC that also lack descending inhibition. ${ }^{71}$

In the large intestine the delay of contractions likely occurs both within the myenteric plexus, possibly because of NO release, and at the level of the muscle because of the predominance of one or other inhibitory neurotransmitters to the muscle (NO, purines and vasoactive inhibitory polypeptide).

From a neurobiological and clinical perspective it is important to understand how a complex neural network like the myenteric plexus, which exists in every region of the GI tract, can give rise to a rhythmic, propagating motor complex: "The possession of knowledge does not kill the sense of wonder and mystery. There is always more mystery." -Anaïs Nin

\section{Mechanisms Underlying the Generation of the Colonic Migrating Motor Complex}

Between CMMCs, ongoing activity in IMNs release both $\mathrm{NO}$ and purines to cause resting membrane hyperpolarization and spontaneous inhibitory junction potentials (IJPs) respectively in the CM, to tonically inhibit the colon. ${ }^{21,25,112}$ Tonic inhibition suppresses motor activity in the colon except during CMMCs. ${ }^{21,81}$ Christensen and colleagues, ${ }^{64}$ who studied the isolated cat colon deduced that "the migrating spike burst represents periodic release of the muscle from the tonic influence of nonadrenergic inhibitory nerves in the intramural plexuses.”

Intracellular electrical recordings from the CM demonstrates that spontaneous CMMCs consist of fast electrical oscillations (1-2 Hz), which give rise to action potentials (about 22 spikes per complex) that are superimposed on a slow prolonged depolarization (about $14 \mathrm{mV}$; duration about 40-60 seconds); ${ }^{25,65,94}$ both phases contribute to contraction (Fig. 2D and 3B). The fast oscillations, superimposed on the slow-depolarizing phase of the CMMC, were thought to be mediated entirely by the release of $\mathrm{ACh}$ from cholinergic motor neurons that fired repetitively to generate a sequence of excitatory junction potentials in the muscle due to synchronization of ascending interneurons. ${ }^{94,103}$ In contrast, it was postulated that the slow depolarization underlying the CMMC is produced by the removal of tonic inhibition 
(disinhibition) at the level of the muscle, possibly by a presynaptic mechanism. ${ }^{94,113}$

More recently, these ideas have been challenged by others using tension recordings placed along the colon that have suggested that the CMMC is entirely due to the activation of EMNs that release $\mathrm{ACh}$ and tachykinins without the necessity of disinhibition. ${ }^{114}$ Using intracellular electrophysiological recordings from the CM we found that both the fast oscillations, as well as the slow depolarization involved the release of $\mathrm{ACh}$ and tachykinins from EMNs rather than disinhibition per se. We proposed that muscarinic and neurokinin-2 (NKII) receptors were located on the muscle and muscarinic and NKI receptors were located on pacemaker ICC. This idea was confirmed by our $\mathrm{Ca}^{2+}$ imaging studies of myenteric neurons and ICC-MY in the whole murine colon. ${ }^{28}$ However, we also found that disinhibition was present, although this is unlikely to be a critical mechanism in CMMC generation since they still occur in the POM-STC mice with suppressed inhibitory nerve pathways (Fig. 2D). ${ }^{81}$ However, as discussed above, descending inhibition (perhaps also disinhibition) is important in CMMC propagation. ${ }^{81}$

\section{Colonic Migrating Motor Complex Generation Requires the Activation of Myenteric Interstitial Cells of Cajal}

The large intestine of most mammals, including mouse and humans, exhibit 2 extensive pacemaker networks that lie mainly on the myenteric (ICC-MY) and submucosal (ICC-SM) sides of the CM. ${ }^{26,115-119}$ ICC-MY, which span and couple the longitudinal muscle cell (LM) and CM layers together, generate a fast electrical rhythm referred to as myenteric potential oscillations (about $16-60 / \mathrm{min}$ ), whereas ICC-SM generate a slower more regular electrical rhythm called slow waves (about 5-16 cycle/min; Fig. 2D and 3B).

Many of these early studies were performed in relatively small strips of colon that lack long intrinsic neural pathways. $\mathrm{Ca}^{2+}$ imaging of activity of myenteric neurons and pacemaker ICCMY in whole isolated colon demonstrated that IMNs were active but ICC-MY were inhibited between CMMCs. ${ }^{26-28}$ Tetrodotoxin blocked the firing in myenteric neurons and increased the activity in ICC-MY. Similarly, L-NA also increased the activity in ICC-MY, suggesting they were inhibited by NO released from IMNs. ${ }^{28}$

Moreover, just prior to the CMMC, some IMNs increase their firing but then reduce their activity for prolonged periods that usually outlasted the duration of the CMMC contraction. ${ }^{28}$
We concluded that the turning off of IMNs during CMMCs likely ensures that EMNs maximally activate ICC-MY and muscle, unrestricted by inhibitory neurotransmitters. During the CMMC, EMNs and ICC-MY fire intensely at a rate similar to the electrical fast oscillations (up to $2 \mathrm{~Hz}$ ) that are superimposed on a slower rise in $\mathrm{Ca}^{2+}$ in ICC-MY, which has a duration sim-

$\mathrm{A}_{\mathrm{Ca}^{2+}}$ transients in myenteric neurons in the murine colon

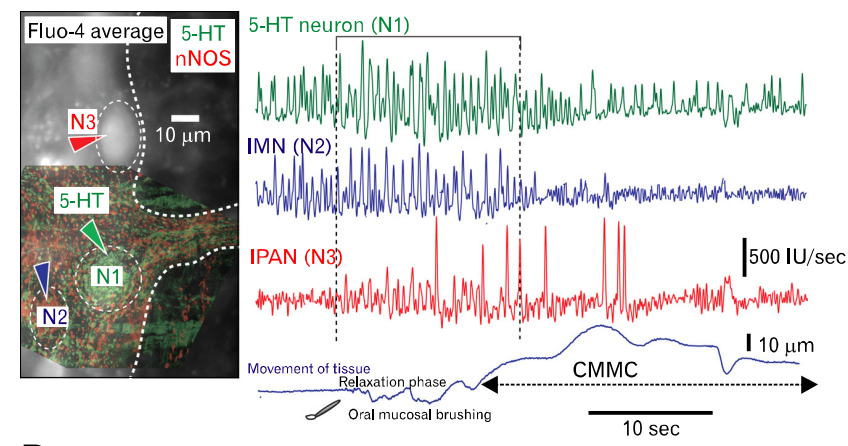

$\mathrm{B}_{\mathrm{Ca}^{2+}}$ transients in ICC-MY and LM between and during a CMMC

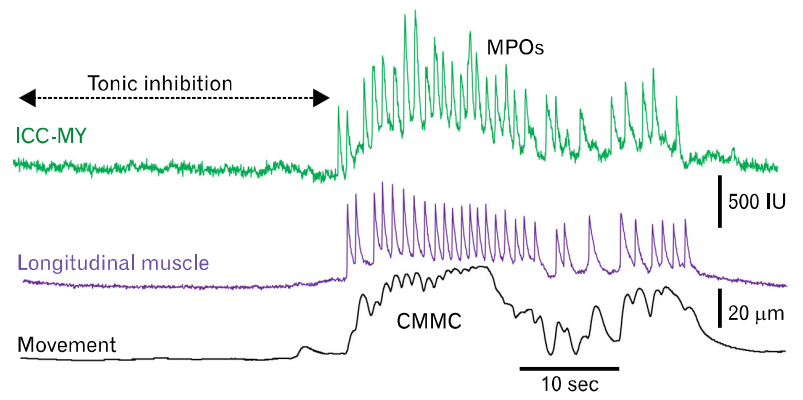

Figure 3. Calcium imaging of myenteric neurons and pacemaker interstitial cells of Cajal (ICC). (A) Differentiated $\mathrm{Ca}^{2+}$ transients in 3 myenteric neurons of the murine mid colon before and during a colonic migrating motor complexes (CMMC; see movement). The CMMC was evoked by gently stroking the mucosa with a brush, at the proximal end of the colon. Neurons were identified later using immunohistochemistry: 5-hydroxytryptamine (5-HT) neuron (N1-green), neuronal nitric oxide synthase (nNOS) inhibitory motor neuron (IMN; N2-blue) and an intrinsic primary afferent neuron (IPAN; N3-red; identified by shape and mitotracker dye $\mathrm{e}^{26}$. Note: (1) 5-HT and the nNOS neuron were spontaneously active. (2) 5-HT neuron increases its activity just before CMMC, as does the IMN. The IPAN appears to fire slightly later. (3) nNOS neuron turns off during the CMMC but 5-HT neuron keeps firing, although at a reduced rate. (4) Firing in IPANs occurs throughout CMMC but stops firing following peak of CMMC contraction (Imaging by Grace Birch and Taka Okamoto). (B) Spontaneous $\mathrm{Ca}^{2+}$ transients in myenteric ICC (ICC-MY) and longitudinal muscle (LM) cell between and during the CMMC. Note that activity in ICC-MY and adjacent LM are closely matched. MPOs, myenteric potential oscillations. 
ilar to the slow depolarization in CM (Fig. 3B). The activity of ICC-MY during the CMMC is closely correlated with similar $\mathrm{Ca}^{2+}$ activity in adjacent $\mathrm{CM}$ and $\mathrm{LM}$ cells (Fig. 3B). What was surprising in these imaging experiments was that ICC-MY in the colon were not well coupled together in the network, even after tetrodotoxin. ${ }^{28,115}$ This contrasts dramatically with the continuous propagation of slow waves through the ICC-MY network in the small intestine. ${ }^{96,120}$ This suggests that excitatory nerves are extremely important in coupling ICC-MY activity to the LM and $\mathrm{CM}$ in the colon (Fig. $1 \mathrm{~A}$ and $3 \mathrm{~B}$ ).

\section{A Action potentials generate $\mathrm{Ca}^{2+}$ transients in all varicosities} along the same nerve fiber
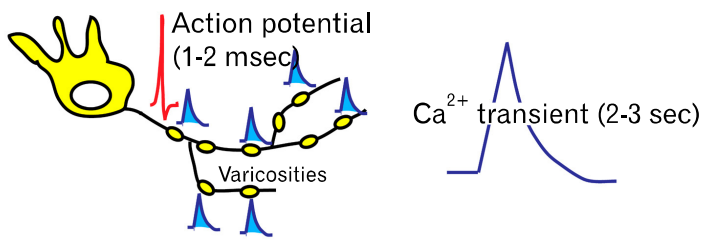

$B_{S}$

$\mathrm{B}_{\text {Spontaneous }} \mathrm{Ca}^{2+}$ transients in varicosities along the same nerve fiber
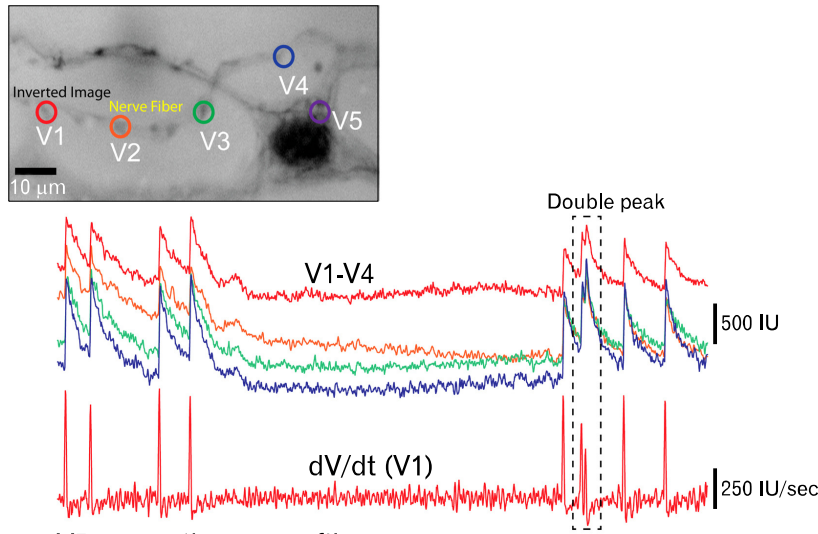

V5 on another nerve fiber

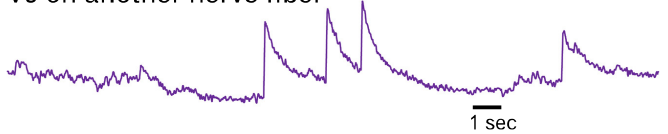

Figure 4. $\mathrm{Ca}^{2+}$ transients in varicosities allow for a measure of action potential firing. (A) A schematic illustration of a neuron with collaterals and varicosities (yellow). As an action potential (duration 1-3 milliseconds) travels down a nerve fiber it depolarizes each varicosity leading to $\mathrm{Ca}^{2+}$ influx through N-type channels (duration 2-3 seconds) and neurotransmitter release. (B) High powered, high frame rate, $\mathrm{Ca}^{2+}$ imaging of spontaneous $\mathrm{Ca}^{2+}$ transients in 4 varicosities (V1-V5) along the same nerve fiber, which had identical activities. Whereas, varicosity $\mathrm{V} 5$ is on another nerve fiber and had a different pattern of activity. Trace $\mathrm{V} 1$ is also differentiated to show $\mathrm{Ca}^{2+}$ spikes generated by action potentials (frame rate $79 \mathrm{~Hz}$; recording by Grace Birch and Robert Corrigan).
Atropine reduced the evoked $\mathrm{Ca}^{2+}$ responses in ICC-MY during the CMMC, and subsequent addition of an NKI antagonist, but not an NKII antagonist, completely blocked the responses of ICC-MY during the CMMC. ${ }^{28}$ Therefore, it appears that the fast oscillations and slow depolarization observed in the muscle during the CMMC are correlated with a similar pattern of $\mathrm{Ca}^{2+}$ activity in ICC-MY; it is likely then, that the pattern of activity in ICC-MY conducts into the $\mathrm{LM}$ and $\mathrm{CM}$ to ensure that the 2 muscles are co-activated during the $\mathrm{CMMC}^{26}$

\section{Myenteric Nerve Fiber Activity Between and During the Colonic Migrating Motor Complex}

By examining the spontaneous and evoked $\mathrm{Ca}^{2+}$ transients in the nerve varicosities (sites of transmitter release) of myenteric axons it has been possible to get some idea of the activity of nerve fibers both between and during the CMMC. ${ }^{27}$ This is possible because as an action potential propagates down a nerve fiber it depolarizes all varicosities along a particular nerve fiber at the same time causing $\mathrm{Ca}^{2+}$ influx and potentially neurotransmitter release (Fig. 4). ${ }^{27}$ Between CMMCs, varicosities fired at a frequency of about $0.6 \mathrm{~Hz}$, which correlates with the frequency of spontaneous IJPs in the CM, suggesting they were mainly in inhibitory nerve pathways. ${ }^{27}$

During a CMMC other previously quiescent varicosities fired up to $2 \mathrm{~Hz}$ for the duration of the CMMC and may have been part of excitatory nerve pathways. ${ }^{27}$ Other varicosities decreased their activity during the CMMC suggesting may have been part of inhibitory nerve pathways. Due to the large number of 5-HT varicosities in myenteric ganglia visualized with immunohistochemistry, many of these active varicosities may have been on 5-HT nerve fibers. Activity in varicosities was correlated with responses in a number of neurons. Although further characterization of the chemical coding of these active varicosities is needed, it does suggest that during the CMMC there is indeed a repetitive firing of varicosities in myenteric ganglia (interneurons) that correlate with the activation of EMNs. ${ }^{103}$

\section{Role of Mucosal and Neuronal 5-hydroxytryptamine in Colonic Migrating Motor Complexes and Enteric Reflexes -}

\section{Enteric Neural Reflexes}

Fecal matter in the large bowel stimulates the mucosa, dis- 
tends and elongates the colon. Each of these is a powerful stimulus for peristaltic reflexes triggered by radial distension and mucosal stimulation, as well as occult reflexes triggered by elongation that can radically influence CMMCs and HAPCs in the colon.

\section{Peristaltic reflexes}

Intraluminal balloon distension can activate both mucosal and stretch activated peristaltic reflexes and CMMCs at the same time. ${ }^{8,24,26,31}$ We define the colonic peristaltic reflex as ascending excitatory and descending inhibitory response to a point of stimulation, ${ }^{121}$ that propagates rapidly through the myenteric plexus compared to a CMMC. However, peristaltic reflex pathways are likely intertwined with the CMMC. Mucosal stimulation releases 5-HT from EC cells that mainly activates $5-\mathrm{HT}_{3}$ receptors on the mucosal endings of myenteric IPANs. ${ }^{24}$ Radial stretch, on the other hand, excites myenteric mechanosensitive interneurons. $^{24,31,121-123}$ Interestingly, mucosal stimulation lowers the threshold for stretch activated reflexes, but not vice versa, implying that IPANs synapse with mechanosensitive sensory interneurons. $^{31,124}$

Therefore, the intestine appears to have IPANs that detect mucosal inputs and muscle tension and mechanosensitive interneurons that detect circumferential stretch, analogous to Golgi tendon organs and muscle spindles in the somatic nervous system. $^{31,125}$

During pellet propulsion, peristaltic reflexes and the CMMC, both the LM and CM layers are innervated so that they can contract or relax together, ${ }^{31,35,70,126,127}$ as originally shown by Bayliss and Starling. ${ }^{128}$

The pressure and shear forces exerted by a fecal pellet in the colon releases 5-HT from the mucosa that entrains the nerve pathways causing CMMCs to propagate more readily in an orthograde direction. ${ }^{24,101}$ This may be, in part, due to modulation of excitability of the ENS by the activation of peristaltic reflex pathways (oral excitation and anal inhibition).

\section{Occult reflexes}

Colonic lengthening appears to be an integral part of normal colonic physiology since its overall effect is to inhibit pellet transit and promote accommodation. ${ }^{77}$ When the guinea-pig and mouse colon fills with fecal pellets its length, but not so much its width, increases dramatically (about $40 \%$ and $20 \%$ in the guinea-pig and mouse colon respectively) and the expulsion rate of fecal pellets is considerably slowed. ${ }^{69,76,77}$

The reflex activated by elongation is called an occult reflex (hidden from view) because it does not appear to have a direct output to the muscle but inhibits neurons in peristaltic nerve circuits. Occult reflexes, like peristaltic reflexes, are also polarized. ${ }^{69,76,77}$ Oral elongation of the colon activates a powerful and dominant inhibitory reflex that reduces or blocks CMMCs for as long as the stimulus is applied, whereas anal elongation activates a single CMMC regardless of stimulus duration. ${ }^{69}$ Oral elongation appears to activate mechanosensitive nNOS positive descending interneurons that release $\mathrm{NO}$ to inhibit many myenteric neurons, including IPANs, thus inhibiting the CMMC, possibly by generating an inhibitory postsynaptic potential in interneurons underlying peristaltic nerve circuits. ${ }^{69,77}$ In contrast, anal elongation appears to activate mechanosensitive cholinergic ascending interneurons that excite myenteric IPANs and other neurons underlying the generation of the CMMC. ${ }^{69}$ If not for the excitatory component of this reflex then the colon would probably not adequately empty.

$\mathrm{NO}$ is an ideal inhibitory neurotransmitter for the dominant inhibitory component of the occult reflex, since mechanosensitive interneurons underlying this neural reflex are always likely to be continuously firing while the colon is elongated. $\mathrm{NO}$ is generated by the $\mathrm{Ca}^{2+}$-dependent enzyme nNOS in axonal varicosities and, unlike most other neurotransmitters stored in vesicles (like ACh), is unlikely to be depleted following repetitive action potentials that depolarize varicosities causing $\mathrm{Ca}^{2+}$ influx.

Currently it is unknown whether 5-HT neurons, like IPANs, or submucous neurons can be inhibited or excited by the occult reflex. ${ }^{69}$

\section{Role of Mucosal 5-hydroxytryptamine in Peristalsis and Colonic Migrating Motor Complex Generation}

Bülbring and colleagues in the 1950s who studied the role of 5 -HT in peristalsis in the guinea-pig small intestine made a series of seminal observations: ${ }^{8,32}$ (1) Increases in intraluminal pressure released 5-HT from EC cells and initiated peristaltic reflexes in vivo and in vitro; (2) Anesthesia, asphyxiation of the mucosa or removal of the mucosa abolished the peristaltic reflex, implying that it is mucosa dependent; (3) Moreover, luminal application of 5-HT initiated the reflex and lowered the threshold for its pressure-induced manifestation; and (4) Low doses of 5-HT added to the serosa initially stimulates and then blocks peristalsis.

Frigo and Lecchini ${ }^{29}$ observed in the isolated colon from cat and guinea-pig that the peristaltic reflex was also dependent upon the mucosa, since they observed that the reflex could not be eli- 
cited from areas from which the mucosal and submucosal layers had been removed and concluded that, “...these layers are essential for the triggering of the peristaltic reflex and for the propulsion of solid contents in the colon...."

Similarly, we observed that removing the mucosa abolished spontaneous CMMCs in the whole isolated murine colon, suggesting that release of 5-HT from EC cells in the mucosa was necessary for initiating CMMCs. ${ }^{21,24-26}$ The preparation was not affected by the dissection technique since CMMCs could be evoked by electric field stimulation (EFS), myenteric neurons exhibited ongoing activity and tonic inhibition of the muscle was still present. ${ }^{8,21,25}$ Moreover, 5- $\mathrm{HT}_{3}$ antagonists reduced or abolished spontaneous or mucosally evoked CMMCs, but did not affect CMMCs evoked by EFS even in preparations without the mucosa. ${ }^{8,21,24}$ This effect is likely mediated by the only class of sensory neuron that projects to the mucosa - the IPAN - as ondansetron reduced the responses in myenteric IPANs generated by mechanical stimulation of the mucosa under the recording site by over $80 \% .^{26}$ Also, when intracellular recordings are made from myenteric neurons in guinea-pig small intestine close to a section of intact mucosa there was a background firing in IPANs that lead to an increased excitability of $\mathrm{S}$ neurons; this increased excitability was absent when the mucosa was removed. ${ }^{130}$ These results strongly suggest that spontaneous or evoked release of 5-HT from mucosal EC cells is normally required to activate myenteric IPANs that in turn excite the neural circuitry underlying the CMMC (Fig. 1A).

Whether it is spontaneous or evoked release of 5-HT from EC cells that is required to initiate the CMMC is unclear. EC cells have a variety of excitatory and inhibitory receptors to excitatory and inhibitory neurotransmitters such as ATP, GABA, $\mathrm{NE}$, NO, muscarinic and vasoactive inhibitory polypeptide receptors. ${ }^{131}$ Its possible that the release of 5-HT from EC cells is normally inhibited by sympathetic nerves or NO.

We propose that HAPCs, like CMMCs, are normally generated by both mucosal and neuronal 5-HT. Mucosal 5-HT does not appear to act directly on enteric neuron cell bodies, since there are a number of barriers that prevent the diffusion of 5-HT to ganglia. ${ }^{32}$ Secretion of 5-HT from EC cells activates the mucosal endings of IPANs in the myenteric and submucous plexus, via $5-\mathrm{HT}_{3}$ and $5-\mathrm{HT}_{1 \mathrm{P}} / 5-\mathrm{HT}_{7}$ receptors respectively (Fig. 1). ${ }^{26,125,126}$ Like a positive feedback loop, IPANS appear to synapse with myenteric 5-HT interneurons that, in turn, synapse with IPANS (Fig. 1). ${ }^{14}$

\section{Role of Neuronal 5-hydroxytryptamine Receptors in Colonic Migrating Motor Complex Generation and Tonic Inhibition}

In the murine colon, serotonergic nerve fiber varicosities are closely associated with 5-HT neurons, IMNs, IPANs, pacemaker ICC networks, intramuscular ICC, glia cells, submucous neurons and nNOS neurons in Henley's plexus. ${ }^{14}$

Adding small amounts of 5-HT to the isolated colon can increase the frequency of spontaneous CMMCs. ${ }^{95}$ 5-HT can also initiate a brief burst of CMMCs in preparations without the mucosa. ${ }^{21}$ However, we found that brief pulses of 5-HT $(0.1$

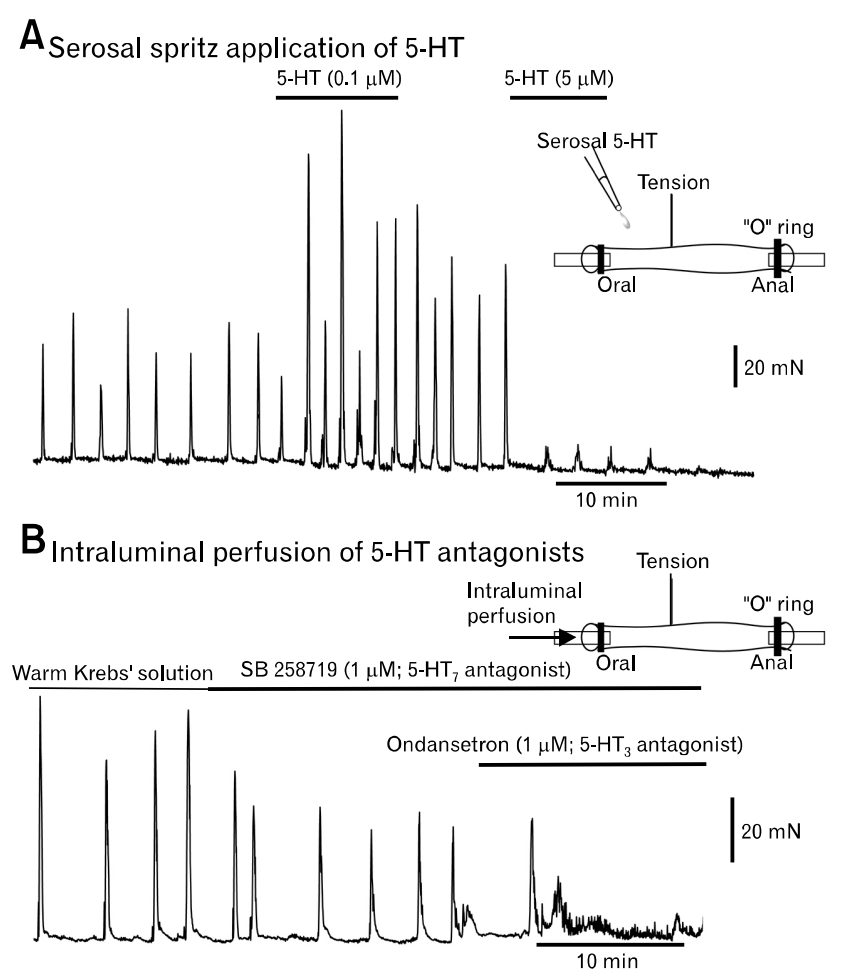

Figure 5. Important role of 5-hydroxytryptamine (5-HT) in colonic migrating motor complex (CMMC) generation. (A) A tension transducer was attached to the surface of the mid isolated murine colon. A spritz of 5 -HT $(0.1 \mu \mathrm{M})$ onto the serosal surface increased the frequency and amplitude of CMMCs. A larger dose of 5-HT ( $5 \mu \mathrm{M})$ blocked the CMMCs. Spritzing pure Krebs' solution had no affect. (B) Intraluminal perfusion of Krebs' solution $\left(35^{\circ} \mathrm{C}\right)$ followed by the addition of a $5-\mathrm{HT}_{7}$ antagonist (SB 258719) reduced the amplitude of CMMCs, which were completely blocked following the further addition of a $5-\mathrm{HT}_{3}$ antagonist (ondansetron) to the lumen. These results suggests that neuronal 5-HT is important in CMMC generation and that both myenteric and submucosal IPANs are involved in initiating the CMMC (experiments performed by Robert Corrigan). 
$\mu \mathrm{M})$ applied to the serosal surface of the murine colon increased the amplitude and frequency of CMMCs, whereas larger doses of 5-HT ( $>5 \mu \mathrm{M}$ ) usually blocked the CMMC, likely by desensitizing 5-HT receptors on myenteric neurons, including IPANs (Fig. 5A). ${ }^{132}$ These experiments imply that neuronal 5 -HT is important in generating and regulating the frequency of CMMCs.

Most studies looking at the role of 5-HT in synaptic transmission using intracellular electrophysiological recordings from myenteric neurons have identified 3 excitatory $\left(5-\mathrm{HT}_{3}, 5-\mathrm{HT}_{4}\right.$ and $5-\mathrm{HT}_{7} / 5-\mathrm{HT}_{1 \mathrm{p}}$ receptors) and 1 inhibitory receptor $\left(5-\mathrm{HT}_{1 \mathrm{~A}}\right)$ for $5-\mathrm{HT}$. The $5-\mathrm{HT}_{3}$ receptor is a ligand gated ion channel, whereas the other receptors are $G$ protein coupled. ${ }^{1}$

Stimulation of serotonergic fibers can elicit fast excitatory synaptic potentials (fEPSPs) mediated by $5-\mathrm{HT}_{3}$ receptors in some $\mathrm{S}$ neurons, and sEPSPs mediated by $5-\mathrm{HT}_{7} / 5-\mathrm{HT}_{1 \mathrm{p}}$ receptors in IPANs; whereas, $5-\mathrm{HT}_{4}$ receptors facilitate ACh release from nerve terminals by a presynaptic mechanism and $5-\mathrm{HT}_{1 \mathrm{~A}}$ receptors cause presynaptic inhibition of fEPSPs and sEPSPs directly hyperpolarizes some IPANs. ${ }^{15,132-135}$

\section{5-hydroxytryptamine $1 \mathrm{~A}$ receptors, an enigma?}

The 5-HT $\mathrm{HA}_{1 \mathrm{~A}}$ receptor is also a $\mathrm{G}$-protein $\left(\mathrm{G}_{\mathrm{i}} / \mathrm{G}_{\mathrm{o}}\right)$ coupled receptor that is coupled to decrease cAMP. ${ }^{1}$ Surprisingly, $5-\mathrm{HT}_{1 \mathrm{~A}}$ receptor antagonists blocked spontaneous CMMCs, as well as CMMCs evoked by EFS in preparations without the mucosa, suggesting that the drug can also act within the myenteric plexus. ${ }^{21}$ One would have expected a $5-\mathrm{HT}_{1 \mathrm{~A}}$ antagonist to remove presynaptic inhibition and enhance SEPSPs $^{133}$ and consequently increase CMMCs.

Currently, however, we know that $5-\mathrm{HT}_{1 \mathrm{~A}}$ receptor antagonists produce an atropine-sensitive depolarization of the muscle and decrease the frequency of CMMCs. After the nicotinic antagonist hexamethonium, which blocks CMMCs (Fig. 2C), the $5-\mathrm{HT}_{1 \mathrm{~A}}$ antagonists had no effect. This suggests that by activating $5-\mathrm{HT}_{1 \mathrm{~A}}$ receptors 5 - $\mathrm{HT}$ neurons may also be important in regulating the output of ascending excitatory neural pathways. ${ }^{21}$ $5-\mathrm{HT}_{1 \mathrm{~A}}$ receptors on the output terminals of IPANs in the myenteric plexus likely play an important role in limiting the neurotransmitter output from IPANs to ascending (S Type I) interneurons. Without this negative feedback there is possibly an excessive release of excitatory neurotransmitter to the muscle. ${ }^{21}$

\section{5-hydroxytryptamine $2 \mathrm{~B}$ receptors}

5- $\mathrm{HT}_{2 \mathrm{~B}}$ receptors are coupled via $\mathrm{G}$ proteins to phospholi- pase C. ${ }^{1} 5-\mathrm{HT}_{2 \mathrm{~B}}$ receptors are important in the development of ICC and a subpopulation of enteric neurons. ${ }^{34,136}$

$5-\mathrm{HT}_{2 \mathrm{~B}}$ receptors were located on the soma and varicose nerve fibers of a sub population of non-5-HT myenteric neurons in the mouse colon, ${ }^{14}$ suggesting that they are both postsynaptic and presynaptic receptors. They also surround and are upon pacemaker ICC suggesting that these receptors may mediate direct responses from serotonergic nerves. ${ }^{14} 5-\mathrm{HT}_{2 \mathrm{~B}}$ receptors have also been observed in myenteric ganglia of the human colon. ${ }^{137}$ What is known is that blocking $5-\mathrm{HT}_{2 \mathrm{~B}}$ receptors reduces the nerve evoked contractions and excitatory responses to 5-HT in human colon and peristaltic contractions in rat colon, implying that targeting this receptor, like the $5-\mathrm{HT}_{4}$ receptor, could be important clinically. ${ }^{137,138}$

\section{5-hydroxytryptamine 3 receptors}

The main effect of antagonizing $5-\mathrm{HT}_{3}$ receptors appear to be related to the release of mucosal 5-HT activation of myenteric IPANs, as described above. ${ }^{21,24}$ However, $5-\mathrm{HT}_{3}$ receptors also appear to be located on IMNs (Fig. 1A). ${ }^{21}$

A $5-\mathrm{HT}_{3}$ antagonist reduces the amplitude of a CMMC, which in the presence of the drug occurs synchronously down the colon. ${ }^{8,24}$ This suggests that the activation of the mucosal endings of myenteric IPANs by mucosal 5-HT was also necessary for activating descending inhibition that is critical for normal CMMC propagation (Fig. 1A). ${ }^{8,21,24}$ The relaxation/hyperpolarization phase preceding the $\mathrm{CMMC}$ is blocked by ondansetron $\left(5-\mathrm{HT}_{3}\right.$ antagonist). ${ }^{21}$ This is especially evident in preparations without the mucosa where EFS evokes a robust hyperpolarization or IJP preceding the CMMC, which is also blocked by ondanstetron; however the excitatory component of the CMMC evoked by EFS was unaffected by the drug. ${ }^{21}$

Between CMMCs the CM is under tonic inhibition that is independent of mucosal 5-HT since it occurs in preparations without the mucosa. ${ }^{25}$ Tonic inhibition of the CM between CMMCs appears to be driven by ongoing activity in descending serotonergic interneurons, which could release both 5-HT and ACh to activate IMNs. ${ }^{21,24,81}$

Others observed that a $5-\mathrm{HT}_{3}$ and a $5-\mathrm{HT}_{4}$ antagonist reduced spontaneous CMMCs in the isolated murine colon devoid of mucosa, ${ }^{19,139}$ suggesting these receptors were important in CMMC generation within the myenteric plexus. This certainly contrasts with our studies on the role of $5-\mathrm{HT}_{3}$ receptors. ${ }^{8}$ However, they never used EFS stimulation to see whether the CMMCs were really abolished by the drug; ${ }^{8}$ perhaps their dissection techni- 
que never removed all mucosal EC cells. We observed that a $5-\mathrm{HT}_{3}$ antagonist (ondansetron) had no effect on spontaneous CMMCs in TPH1 KO mice that lack mucosal 5-HT. ${ }^{8}$

Submucosal neurons are strongly excited during the CMMC, especially just prior to the CMMC, suggesting they are mainly activated during the phase of descending inhibition (Fig. 1A). ${ }^{20}$ The responses in submucosal neurons are significantly reduced by a $5-\mathrm{HT}_{3}$ antagonist (e.g., ondansetron). ${ }^{20}$ This suggests that myenteric descending 5-HT neurons activate secretomotor neurons during the CMMC to produce an increase in secretion to lubricate and facilitate fecal pellet propulsion.

\section{5-hydroxytryptamine 7 receptors}

The $5-\mathrm{HT}_{7}$ receptor is a $\mathrm{G}$-protein $\left(\mathrm{G}_{\mathrm{s}}\right)$ coupled to increases in cAMP, ${ }^{1}$ which is known to excite myenteric IPANs (Fig. 1A). ${ }^{140}$ The $5-\mathrm{HT}_{7}$ receptor is likely the same as the $5-\mathrm{HT}_{1 \mathrm{p}}$, which has never been cloned, and elicits similar responses in IPANs. ${ }^{15,141}$ 5- $\mathrm{HT}_{7}$ antagonists block spontaneous CMMCs. ${ }^{21}$ Importantly, they also block CMMCs evoked by EFS in preparations devoid of mucosa, without affecting the resting membrane potential or spontaneous and evoked IJPs in the CM, suggesting the $5-\mathrm{HT}_{7}$ antagonists were acting in the myenteric plexus. ${ }^{21}$ These results are consistent with the hypothesis that descending serotonergic interneurons are not only synapsing with $\mathrm{IMNs}$ via $5-\mathrm{HT}_{3}$ receptors but are also causing a $5-\mathrm{HT}_{7}$ receptor-mediated sEPSP in IPANs $^{15}$ that appear to be essential for generating the CMMC.

Furthermore, $5-\mathrm{HT}_{7}$ receptors could also be located on the mucosal endings of submucosal IPANs. In fact, intraluminal perfusion of a $5-\mathrm{HT}_{7}$ antagonist reduces the amplitude of CMMCs, which can be completely blocked by the further addition of a $5-\mathrm{HT}_{3}$ antagonist (ondansetron; Fig. 5B).

\section{Controversies Involving the Role of Mucosal and Neuronal 5-hydroxytryptamine}

In this section we specifically address some inconsistencies between research groups that study the CMMC. While some information presented below has been mentioned above, here we comment on specific controversies, and offer some further explanations to the different findings.

\section{Colonic Migrating Motor Complexes and Pellet Propulsion Without the Mucosa}

Peristaltic reflexes can be activated by radial stretch and by pressure or mechanical stimulation of the mucosa. ${ }^{121,123,126,127,142}$ Normally both stimuli are activated at the same time and converge onto common nerve pathways. ${ }^{31,143}$

Recently, it has been shown that fecal pellet propulsion along the guinea-pig isolated colon and CMMCs in the isolated murine colon still occur following removal of the mucosa, suggesting that mucosal 5-HT is unnecessary for peristalsis or CMMCs. ${ }^{143,144}$ Part of the explanation may be due to the size of the fecal pellets, which appear to be larger than normal, ${ }^{143}$ creating considerable distension/radial stretch of the colonic wall. In a related issue about stretch, CMMCs were observed in preparations both with and without the mucosa, although the frequencies of CMMCs were reduced in preparations without the mucosa. ${ }^{145} \mathrm{We}$ contend that the reason that CMMCs were observed in their mucosal free preparations was most likely due to their rake method for recording tension that produced excessive amounts of circumferential stretch, ${ }^{146}$ as the same group have confirmed that they rarely observe spontaneous CMMCs in their preparations without circumferential stretch. ${ }^{147}$

Also, their CMMCs do not often appear to propagate but occur almost synchronously along the colon, ${ }^{143}$ suggesting that descending inhibition is compromised in their preparations. Furthermore, the same group can rarely, if at all, evoke the very sensitive mucosal reflex. ${ }^{143}$ This suggests that descending inhibition and mucosal 5-HT release are suppressed in their mice possibly because of elevated levels of prostaglandins that can occur in low grade inflammations. ${ }^{81}$ Our control mice have minimal endogenous prostaglandins levels because they are held in a clean transgenic animal facility. ${ }^{8,81}$ The effect of different animal housing environments and inflammation on CMMCs would be useful to examine; especially as it relates to a number of inflammatory GI disorders that have abnormal motility patterns.

\section{Lessons From Tryptophan Hydroxylase 1 Knockout Mice That Lack Mucosal 5-hydroxytryptamine}

The genetic deletion of TPH1 in mucosal EC cells has been reported to not alter murine total gut transit time, gastric emptying, small bowel propulsion or rate of expulsion of beads inserted into the rectum. ${ }^{34}$ These observations have led to the suggestion that mucosal 5-HT may not be essential for constitutive gastrointestinal motility. In support of this idea, the daily fecal output of $\mathrm{TPH} 1 \mathrm{KO}$ mice was equal to or greater than that in control mice. $^{8}$

However, the isolated colon of TPH1 KO mice display signs 
of slow transit constipation ${ }^{8}$ since compared to control they have: (1) an elongated impacted colon; (2) larger fecal pellets; (3) slow fecal pellet propulsion in the isolated colon; (4) a longer emptying time; (5) retrograde propulsion of fecal pellets; (6) only rarely propagated CMMCs, which usually occurred synchronously likely due to a lack of descending inhibition; (7) spontaneous CMMCs in the absence of mucosal 5-HT; (8) exhibited reduced $\mathrm{CMMCs}$ and inhibitory responses to intraluminal distension; (9) CMMCs that were resistant to ondansetron; and (10) no mucosal reflexes.

The importance of mucosal 5-HT in propulsion is suggested by the observation that small fecal pellets, which don't significantly distend the colonic wall, are propagated down the control colon. ${ }^{8}$ However, in the colon of TPH1 KO mice, which lacks mucosal 5-HT and consequently has no mucosal reflexes, only larger fecal pellets effectively propagate down the isolated colon, but at a much lower velocity ( $28 \%$ of control) compared to wild type mouse colon. The motility phenotype in TPH1 KO mice was similar to that in POM-STC.

\section{Why Are Colonic Migrating Motor Complexes Generated in the Absence of Mucosal 5-hydroxytryptamine}

In both the POM-STC ${ }^{81}$ and $\mathrm{TPH} 1 \mathrm{KO}^{8}$ mouse colon, spontaneous CMMCs also occurred but they did not effectively propagate because of a lack of mucosal reflexes. In the POMSTC mice this was due to an upregulation of Cox-2 in glia cells and the mucosa that suppressed descending inhibitory nerve pathways and mucosal reflexes. ${ }^{8}$ However, in the POM-STC mouse model propagating CMMCs and mucosal reflexes were observed following a Cox-2 inhibitor. This suggests that there is an increase in prostaglandins (possibly PGE2) in mice when mucosal 5-HT is absent or inhibited that leads to an upregulation of activity in possibly 5-HT neurons and/or IPANs. Spontaneous CMMCs are also observed in TPH1 KO mice (see below) POM-STC, which lack mucosal reflexes, however CMMCs in these mice rarely propagate because of compromised descending inhibition.

It is possible that in the absence of mucosal 5-HT there is a compensatory increase in the excitability of 5-HT neurons or IPANs to allow CMMC generation to continue, although propagation is still likely to be compromised because of lack of mucosal reflexes. ${ }^{8}$ If compromised tonic inhibition occurred, as it certainly does in POM-STC mice, then an increase in muscle tension could activate IPANs and perhaps even 5-HT neurons. ${ }^{26,31,102}$

\section{Can Reserpine Be Used to Deplete Both Mucosal and Neuronal 5-hydroxytryptamine?}

Bülbring and $\mathrm{Crema}^{148}$ were unable to decide whether mucosal 5-HT was essential for the peristaltic reflex because they were unable to deplete mucosal 5-HT stores completely with reserpine.

It has recently been proposed that neither neuronal nor mucosal 5-HT are important for fecal pellet propulsion or spontaneous CMMCs, since these were unaffected by reserpine pretreatment, which purportedly depleted all 5-HT from the colon. ${ }^{19,139,149}$ Reserpine does not affect the synthesis of 5-HT by TPH but inhibits the vesicular monoamine transporter (reviewed in ${ }^{8}$ ); it does however deplete the brain of over $80 \%$ of its $5-\mathrm{HT}^{150}$ and appears to deplete myenteric ganglia of 5-HT. ${ }^{33,139}$

Moreover, it has been known since the 1980s that nerve varicosities have several vesicle compartments for a particular neurotransmitter; ${ }^{150,151}$ the larger storage or reserved pool contains the majority of stored 5-HT that is not directly affected by nerve stimulation, whereas the releasable pool of 5-HT is readily replenished and activated by nerve stimulation. Reserpine depletes the larger storage pool of 5-HT, which gives the impression of 5-HT depletion, but actually does not effect the releasable pool of $5-\mathrm{HT} ;{ }^{150}$ therefore, the readily releasable pool of 5-HT is likely to remain unaffected, particularly if newly synthesized 5-HT in neurons and EC cells is packaged in the vesicles of the releasable pool. ${ }^{150}$ As a matter of fact, reserpine has been consistently used to study the characteristics of the releasable pool of 5-HT and other amines. ${ }^{150,152,153}$

Other groups reported they found that $5-\mathrm{HT}_{3}$ and $5-\mathrm{HT}_{4}$ antagonists inhibited CMMCs and pellet propulsion in their reserpinized animals, ${ }^{19,139,149}$ however, since the releasable pool of 5-HT was likely to be still intact it seems somewhat presumptive to postulate a non-neuronal 5-HT independent mechanism of these antagonists. ${ }^{19,139}$

\section{Conclusions}

HAPCs in vivo appear to be normally inhibited by sympathetic nerve stimulation and/or occult reflexes. Removing the colon from the body removes extrinsic inputs and causes CMMCs to occur rhythmically. The frequency and duration of CMMCs in the isolated human and murine colon are similar in frequency and duration, as are HAPCs in vivo. Descending inhibition is essential for the orderly propagation of CMMCs, 


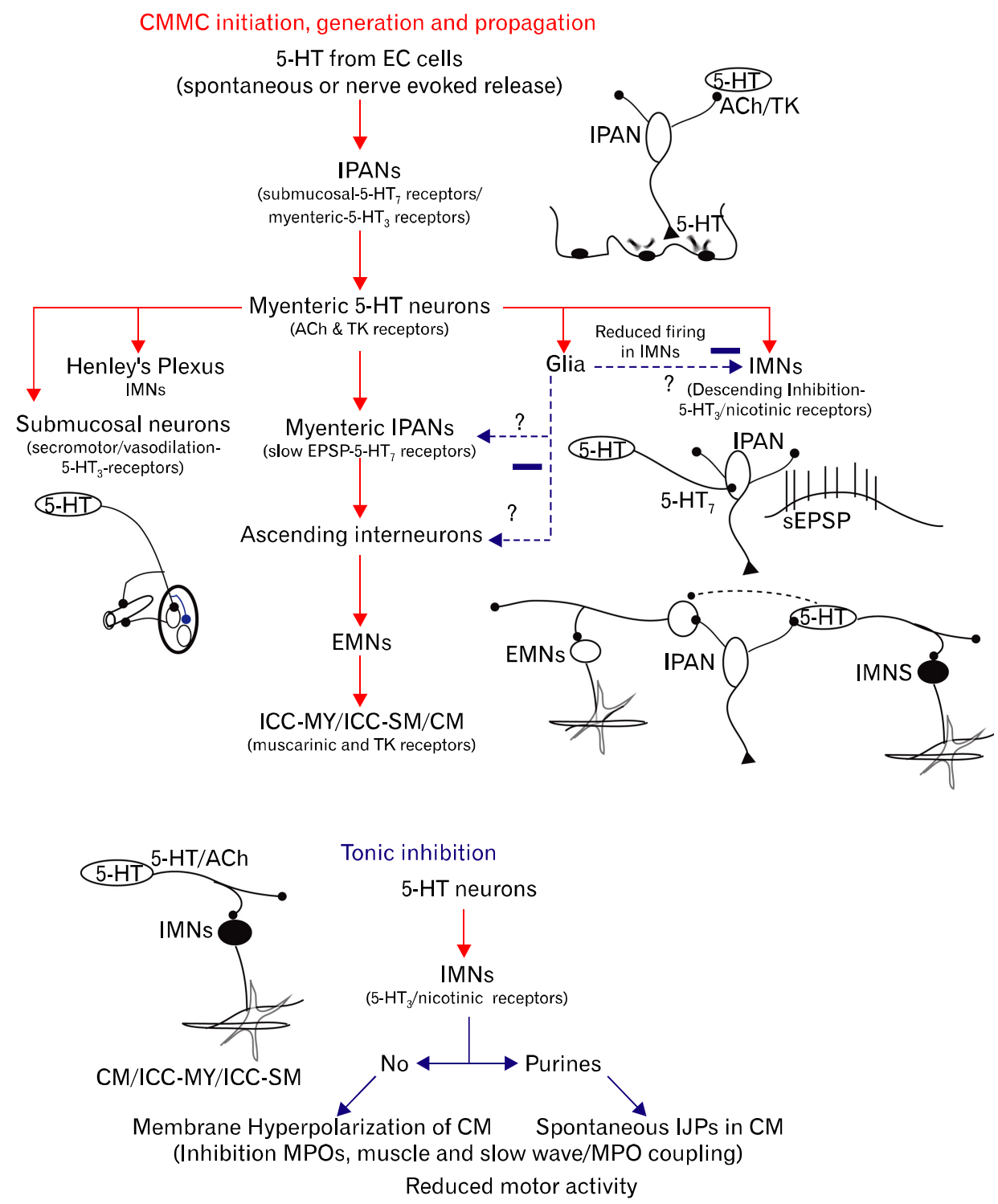

Figure 6. Schematic showing the possible sequence of events underlying the generation of a colonic migrating motor complex (CMMC) and tonic inhibition. CMMC: (1) mucosal release of 5-HT excites intrinsic primary afferent neurons (IPANs) that in turn activate myenteric 5-HT interneurons and motor neurons, (2) 5-HT neurons excite distal IPANs by activating $5-\mathrm{HT}_{7}$ receptors to generate a slow excitatory postsynaptic potential (sEPSP), i.e., change their relatively inexcitable state to an excitable state, (3) IPANs, and perhaps 5-HT neurons, synapse with ascending excitatory nerve pathways, (4) activation of excitatory motor neurons (EMNs) that excite myenteric interstitial cells of Cajal (ICC-MY) to couple activity to longitudinal muscle (LM) and circular muscle (CM), (5) during the contractile phase of the CMMC, inhibitory motor neurons (IMNs) switch off for an extended period of time to allow full excitation of ICC-MY, (6) for the CMMC to propagate, activation of mucosal 5-HT leads to a strong activation of serotonergic descending inhibitory nerve pathways in the first phase of the CMMC and (7) couples this activity to secretomotor activity and blood flow. Glial cells by releasing nitric oxide (NO) or prostaglandins may reduce activity in enteric neurons. Tonic inhibition: (1) 5-HT neurons are spontaneously active and excite IMNs. (2) IMNs, which release NO and purines, inhibit pacemaker ICC-MY and the CM preventing myenteric potential oscillations (MPOs) and slow waves coupling to the muscle, and thereby inhibiting motor activity. EC, enterochromaffin; ACh, acetylcholine; TK, tachykinins; ICC-SM, submucosal ICC.

whereas tonic inhibition is necessary to prevent unproductive contractions.

Mucosal and neuronal 5-HT are normally synergistic, since both are necessary for the normal initiation and generation as well as the effective propagation of CMMCs and consequently propulsion of contents. During outlet obstruction induced STC de- 
scending inhibition and mucosal 5-HT release appear to be compromised because of an upregulation of prostaglandins, leading to slow transit.

The role of 5-HT in a possible sequence of activation of enteric neurons involved in the CMMC and tonic inhibition is shown in Figure 6. However, this is a very linear and simplified description of what is likely occurring in this complex integrated neural network, which has a multitude of synaptic connections, and interacting excitatory and inhibitory neural pathways along the whole colon. 5-HT is likely released from many EC cells along the colon, and could possibly excite, via myenteric and submucosal IPANs, many neurons in interacting nerve pathways.

Despite a number of controversies, which need to be resolved, we are getting closer to understanding how colonic motor behavior switches from one state to another. Clearly, neurally driven colonic peristaltic contractions are normally integrated phenomena that involve various cell types (EC cells, neurons, glia, ICC and smooth muscle cells) across the whole colonic wall from the mucosa to the serosa.

Myenteric 5-HT neurons, despite their small numbers, appear to be an essential player in colonic motility, as attested by their multiple receptors and extensive projections throughout the ENS and pacemaker networks. Despite their rarity, 5-HT neurons likely play a central role in coordinating behavior both along the large intestine and between different cell types in the gut wall.

\section{Future Directions}

To inactivate specific proteins important to the function of 5-HT neurons or pathways in which 5-HT plays a role (synthesis enzymes, receptors, etc), conditional knockout mice will be a better approach, since they likely will not have time to go through developmental and adaptive changes that may confuse interpretation. To start to unravel this enteric neural network complexity underlying the CMMC it will be necessary improve the resolution by which we can record activity of 5-HT neurons, as well as activate and inactive 5-HT neurons and other neurons at will. To visualize the behavior of 5-HT neurons and other neurons in the neural network genetically encoded $\mathrm{Ca}^{2+}$ reporters such as GCAMP3 could be inserted into specific populations of neuons. ${ }^{154,155}$ To activate or inactivate 5-HT neurons, or neurons involved in 5-HT pathways, genetically encoded rhodopsin channels that can be turned on or off by light, can be inserted into specific populations of enteric neurons. ${ }^{156}$ These new tools should offer some exciting insights into the role of 5-HT in colonic motility.

\section{Acknowledgements}

We would like to thank all our current collaborators, especially Dr Sang Don Koh, Dr Tom Gould and Dr Dante Heredia, as well as all our past collaborators that have made significant contributions to our current ideas and understanding of the neural pathways underlying colonic motility.

\section{References}

1. Beattie DT, Smith JA. Serotonin pharmacology in the gastrointestinal tract: a review. Naunyn Schmiedebergs Arch Pharmacol 2008;377:181-203.

2. Gershon MD, Tack J. The serotonin signaling system: from basic understanding to drug development for functional GI disorders. Gastroenterology 2007;132:397-414.

3. Sanger GJ. 5-hydroxytryptamine and the gastrointestinal tract: where next? Trends Pharmacol Sci 2008;29:465-471.

4. Spiller R. Serotonin and GI clinical disorders. Neuropharmacology 2008;55:1072-1080.

5. Gershon MD. Serotonin is a sword and a shield of the bowel: serotonin plays offense and defense. Trans Am Clin Climatol Assoc 2012;123:268-280; discussion 280.

6. Mawe GM, Hoffman JM. Serotonin signalling in the gut--functions, dysfunctions and therapeutic targets. Nat Rev Gastroenterol Hepatol 2013;10:473-486.

7. Peroutka SJ. 5-Hydroxytryptamine receptors in vertebrates and invertebrates: why are there so many? Neurochem Int 1994;25:533536.

8. Heredia DJ, Gershon MD, Koh SD, Corrigan RD, Okamoto T, Smith TK. Important role of mucosal serotonin in colonic propulsion and peristaltic reflexes: in vitro analyses in mice lacking tryptophan hydroxylase 1. J Physiol 2013;591(Pt 23):5939-5957.

9. Hasler WL. Serotonin and the GI tract. Curr Gastroenterol Rep 2009;11:383-391.

10. Hoffman JM, Tyler K, MacEachern SJ, et al. Activation of colonic mucosal $5-\mathrm{HT}_{4}$ receptors accelerates propulsive motility and inhibits visceral hypersensitivity. Gastroenterology 2012;142:844-854, e4.

11. Poole DP, Xu B, Koh SL, et al. Identification of neurons that express 5-hydroxytryptamine4 receptors in intestine. Cell Tissue Res 2006;325:413-422.

12. Jin JG, Foxx-Orenstein AE, Grider JR. Propulsion in guinea pig colon induced by 5-hydroxytryptamine (HT) via $5-\mathrm{HT}_{4}$ and 5-HT 3 receptors. J Pharmacol Exp Ther 1999;288:93-97.

13. Grider JR, Kuemmerle JF, Jin JG. 5-HT released by mucosal stimuli initiates peristalsis by activating $5-\mathrm{HT}_{4} / 5-\mathrm{HT}_{1 \mathrm{p}}$ receptors on sensory CGRP neurons. Am J Physiol 1996;270(5 Pt 1):G778-G782.

14. Okamoto T, Barton MJ, Hennig GW, et al. Extensive projections of myenteric serotonergic neurons suggest they comprise the central processing unit in the colon. Neurogastroenterol Motil 2014;26: 556-570. 
15. Monro RL, Bornstein JC, Bertrand PP. Slow excitatory post-synaptic potentials in myenteric AH neurons of the guinea-pig ileum are reduced by the 5-hydroxytryptamine7 receptor antagonist SB 269970. Neuroscience 2005;134:975-986.

16. Tonini M, Vicini R, Cervio E, et al. 5- $\mathrm{HT}_{7}$ receptors modulate peristalsis and accommodation in the guinea pig ileum. Gastroenterology 2005;129:1557-1566.

17. Irving HR, Tan YY, Tochon-Danguy N, et al. Comparison of $5-\mathrm{HT}_{4}$ and $5-\mathrm{HT}_{7}$ receptor expression and function in the circular muscle of the human colon. Life Sci 2007;80:1198-1205.

18. Crowell MD, Shetzline MA, Moses PL, Mawe GM, Talley NJ. Enterochromaffin cells and 5-HT signaling in the pathophysiology of disorders of gastrointestinal function. Curr Opin Investig Drugs 2004;5:55-60.

19. Sia TC, Whiting M, Kyloh M, et al. 5- $\mathrm{HT}_{3}$ and $5-\mathrm{HT}_{4}$ antagonists inhibit peristaltic contractions in guinea-pig distal colon by mechanisms independent of endogenous 5-HT. Front Neurosci 2013;7: 136.

20. Hennig GW, Gregory S, Brookes SJ, Costa M. Non-peristaltic patterns of motor activity in the guinea-pig proximal colon. Neurogastroenterol Motil 2010;22:e207-e217.

21. Dickson EJ, Heredia DJ, Smith TK. Critical role of $5-\mathrm{HT}_{1 \mathrm{~A}}$, $5-\mathrm{HT}_{3}$, and $5-\mathrm{HT}_{7}$ receptor subtypes in the initiation, generation, and propagation of the murine colonic migrating motor complex. Am J Physiol Gastrointest Liver Physiol 2010;299:G144-G157.

22. Okamoto T, Bayguinov PO, Broadhead MJ, Smith TK. Ca ${ }^{2+}$ transients in submucous neurons during the colonic migrating motor complex in the isolated murine large intestine. Neurogastroenterol Motil 2012;24:769-778, e354.

23. Dinning PG, Arkwright JW, Costa M, et al. Temporal relationships between wall motion, intraluminal pressure, and flow in the isolated rabbit small intestine. Am J Physiol Gastrointest Liver Physiol 2011;300:G577-G585.

24. Heredia DJ, Dickson EJ, Bayguinov PO, Hennig GW, Smith TK. Localized release of serotonin (5-hydroxytryptamine) by a fecal pellet regulates migrating motor complexes in murine colon. Gastroenterology 2009;136:1328-1338.

25. Dickson EJ, Heredia DJ, McCann CJ, Hennig GW, Smith TK. The mechanisms underlying the generation of the colonic migrating motor complex in both wild-type and nNOS knockout mice. Am J Physiol Gastrointest Liver Physiol 2010;298:G222-G232.

26. Bayguinov PO, Hennig GW, Smith TK. Calcium activity in different classes of myenteric neurons underlying the migrating motor complex in the murine colon. J Physiol 2010;588(Pt 3):399-421.

27. Bayguinov PO, Broadhead MJ, Okamoto T, Hennig GW, Smith TK. Activity in varicosities within the myenteric plexus between and during the colonic migrating motor complex in the isolated murine large intestine. Neurogastroenterol Motil 2012;24:e185-e201.

28. Bayguinov PO, Hennig GW, Smith TK. $\mathrm{Ca}^{2+}$ imaging of activity in ICC-MY during local mucosal reflexes and the colonic migrating motor complex in the murine large intestine. J Physiol 2010;588(Pt 22):4453-4474.

29. Knowles CH, Martin JE. Slow transit constipation: a model of human gut dysmotility. Review of possible aetiologies. Neurogastroenterol Motil 2000;12:181-196.

30. Spiller R. Role of motility in chronic diarrhoea. Neurogastroenterol
Motil 2006;18:1045-1055.

31. Smith TK, Spencer NJ, Hennig GW, Dickson EJ. Recent advances in enteric neurobiology: mechanosensitive interneurons. Neurogastroenterol Motil 2007;19:869-878.

32. Gershon MD. 5-Hydroxytryptamine (serotonin) in the gastrointestinal tract. Curr Opin Endocrinol Diabetes Obes 2013;20:14-21.

33. Costa M, Furness JB, Cuello AC, Verhofstad AA, Steinbusch HW, Elde RP. Neurons with 5-hydroxytryptamine-like immunoreactivity in the enteric nervous system: their visualization and reactions to drug treatment. Neuroscience 1982;7:351-363.

34. Li Z, Chalazonitis A, Huang YY, et al. Essential roles of enteric neuronal serotonin in gastrointestinal motility and the development/survival of enteric dopaminergic neurons. J Neurosci 2011; 31:8998-9009.

35. Spencer N, McCarron SL, Smith TK. Sympathetic inhibition of ascending and descending interneurones during the peristaltic reflex in the isolated guinea-pig distal colon. J Physiol 1999;519(Pt 2):539-550.

36. Meedeniya AC, Brookes SJ, Hennig GW, Costa M. The projections of 5-hydroxytryptamine-accumulating neurones in the myenteric plexus of the small intestine of the guinea-pig. Cell Tissue Res 1998;291:375-384.

37. Sang Q, Williamson S, Young HM. Projections of chemically identified myenteric neurons of the small and large intestine of the mouse. J Anat 1997;190(Pt 2):209-222.

38. Wardell CF, Bornstein JC, Furness JB. Projections of 5-hydroxytryptamine-immunoreactive neurons in guinea-pig distal colon. Cell Tissue Res 1994;278:379-387.

39. Lomax AE, Furness JB. Neurochemical classification of enteric neurons in the guinea-pig distal colon. Cell Tissue Res 2000;302: 59-72.

40. Barbiers M, Timmermans JP, Adriansen D, De Groodt-Lasseel MH, Scheuermann DW. Projections of neurochemically specified neurons in the porcine colon. Histochem Cell Biol 1995;103:115-126.

41. Lolova I, Davidoff M, Itzev D, Apostolov A. Histochemical, immunocytochemical and ultrastructural data on the innervation of the smooth muscle of the large intestine in Hirschsprung's disease. Acta Physiol Pharmacol Bulg 1986;12:55-62.

42. Sharrad DF, Chen BN, Brookes SJ. Neurochemical coding compared between varicose axons and cell bodies of myenteric neurons in the guinea-pig ileum. Neurosci Lett 2013;534:171-176.

43. Kirchgessner AL, Liu MT, Tamir H, Gershon MD. Identification and localization of $5-\mathrm{HT}_{1 \mathrm{P}}$ receptors in the guinea pig pancreas. Am J Physiol 1992;262(3 Pt 1):G553-G566.

44. Karhula T, Soinila S, Lakomy M, Majewski M, Kaleczyk J, Häppölä O. 5-Hydroxytryptamine-immunoreactive nerve fibers in the rat and porcine prevertebral sympathetic ganglia: effect of precursor loading and relation to catecholaminergic neurons. Neurosci Lett 1995;194:85-88.

45. Griffith SG, Burnstock G. Immunohistochemical demonstration of serotonin in nerves supplying human cerebral and mesenteric blood-vessels. Some speculations about their involvement in vascular disorders. Lancet 1983;1:561-562.

46. Tassicker BC, Hennig GW, Costa M, Brookes SJ. Rapid anterograde and retrograde tracing from mesenteric nerve trunks to the guinea-pig small intestine in vitro. Cell Tissue Res 1999;295:437-452. 
47. Spencer NJ, Bywater RA, Klemm MF. Effects of sympathetic nerve stimulation on membrane potential in the circular muscle layer of mouse distal colon. Neurogastroenterol Motil 1998;10:543-552.

48. Bulbring E, Gershon MD. Serotonin participation in the vagal inhibitory pathway to the stomach. Adv Pharmacol 1968;6(Pt A):323-333.

49. Schwartz JH, Shkolnik LJ. The giant serotonergic neuron of Aplysia: a multi-targeted nerve cell. J Neurosci 1981;1:606-619.

50. Hörner M, Weiger WA, Edwards DH, Kravitz EA. Excitation of identified serotonergic neurons by escape command neurons in lobsters. J Exp Biol 1997;200(Pt 14):2017-2033.

51. Alkatout BA, Marvin NM, Crisp KM. Serotonin delays habituation of leech swim response to touch. Behav Brain Res 2007;182: 145-149.

52. Katz PS, Harris-Warrick RM. Recruitment of crab gastric mill neurons into the pyloric motor pattern by mechanosensory afferent stimulation. J Neurophysiol 1991;65:1442-1451.

53. Sanders KM, Smith TK. Motoneurones of the submucous plexus regulate electrical activity of the circular muscle of canine proximal colon. J Physiol 1986;380:293-310.

54. Edwards DH, Heitler WJ, Krasne FB. Fifty years of a command neuron: the neurobiology of escape behavior in the crayfish. Trends Neurosci 1999;22:153-161.

55. Antonsen BL, Edwards DH. Mechanisms of serotonergic facilitation of a command neuron. J Neurophysiol 2007;98:3494-3504.

56. Goyal RK, Chaudhury A. Physiology of normal esophageal motility. J Clin Gastroenterol 2008;42:610-619.

57. Gonzalez A, Sarna SK. Neural regulation of in vitro giant contractions in the rat colon. Am J Physiol Gastrointest Liver Physiol 2001;281:G275-G282.

58. Sarna SK. Myoelectric correlates of colonic motor complexes and contractile activity. Am J Physiol 1986;250(2 Pt 1):G213-G220.

59. Sarna SK, Condon R, Cowles V. Colonic migrating and nonmigrating motor complexes in dogs. Am J Physiol 1984;246(4 Pt 1):G355-G360.

60. Sarna SK, Prasad KR, Lang IM. Giant migrating contractions of the canine cecum. Am J Physiol 1988;25(4 Pt 1):G595-G601.

61. Dinning PG, Szczesniak MM, Cook IJ. Twenty-four hour spatiotemporal mapping of colonic propagating sequences provides pathophysiological insight into constipation. Neurogastroenterol Motil 2008;20:1017-1021.

62. Bassotti G, Gaburri M. Manometric investigation of high-amplitude propagated contractile activity of the human colon. Am J Physiol 1988;255(5 Pt 1):G660-G664.

63. Bharucha AE. High amplitude propagated contractions. Neurogastroenterol Motil 2012;24:977-982.

64. Brann L, Wood JD. Motility of the large intestine of piebald-lethal mice. Am J Dig Dis 1976;21:633-640.

65. Bywater RA, Small RC, Taylor GS. Neurogenic slow depolarizations and rapid oscillations in the membrane potential of circular muscle of mouse colon. J Physiol 1989;413:505-519.

66. Bywater RA, Spencer NJ, Fida R, Taylor GS. Second-, minuteand hour-metronomes of intestinal pacemakers. Clin Exp Pharmacol Physiol 1998;25:857-861.

67. Christensen J, Anuras S, Arthur C. Influence of intrinsic nerves on the electromyogram of cat colon. Migrating spike bursts and elec- trical slow waves in the cat colon: effect of sectioning. Am J Physiol 1978;234:641-647.

68. Dinning PG, Szczesniak M, Cook IJ. Removal of tonic nitrergic inhibition is a potent stimulus for human proximal colonic propagating sequences. Neurogastroenterol Motil 2006;18:37-44.

69. Heredia DJ, Dickson EJ, Bayguinov PO, Hennig GW, Smith TK. Colonic elongation inhibits pellet propulsion and migrating motor complexes in the murine large bowel. J Physiol 2010;588(Pt 15): 2919-2934.

70. Spencer NJ, Bayguinov P, Hennig GW, et al. Activation of neural circuitry and $\mathrm{Ca}^{2+}$ waves in longitudinal and circular muscle during CMMCs and the consequences of rectal aganglionosis in mice. Am J Physiol Gastrointest Liver Physiol 2007;292:G546-G555.

71. Zarate N, Spencer NJ. Chronic constipation: lessons from animal studies. Best Pract Res Clin Gastroenterol 2011;25:59-71.

72. Crowell MD, Bassotti G, Cheskin LJ, Schuster MM, Whitehead WE. Method for prolonged ambulatory monitoring of high-amplitude propagated contractions from colon. Am J Physiol 1991;261(2 Pt 1):G263-G268.

73. Bharucha AE, Camilleri M, Zinsmeister AR, Hanson RB. Adrenergic modulation of human colonic motor and sensory function. Am J Physiol 1997;273:G997-G1006.

74. Leelakusolvong S, Bharucha AE, Sarr MG, Hammond PI, Brimijoin S, Phillips SF. Effect of extrinsic denervation on muscarinic neurotransmission in the canine ileocolonic region. Neurogastroenterol Motil 2003;15:173-186.

75. Leelakusolvong S, Sarr MG, Miller SM, Phillips SF, Bharucha AE. Role of extrinsic innervation in modulating nitrergic transmission in the canine ileocolonic region. Am J Physiol 2002;283: G230-G239.

76. Dickson EJ, Hennig GW, Heredia DJ, et al. Polarized intrinsic neural reflexes in response to colonic elongation. J Physiol 2008;586 (Pt 17):4225-4240.

77. Dickson EJ, Spencer NJ, Hennig GW, et al. An enteric occult reflex underlies accommodation and slow transit in the distal large bowel. Gastroenterology 2007;132:1912-1924.

78. Dinning PG, Zarate N, Szczesniak MM, et al. Bowel preparation affects the amplitude and spatiotemporal organization of colonic propagating sequences. Neurogastroenterol Motil 2010;22:633, e176.

79. Lémann M, Flourié B, Picon L, Coffin B, Jian R, Rambaud JC. Motor activity recorded in the unprepared colon of healthy humans. Gut 1995;37:649-653.

80. Sood MR, Rudolph CD. Gastrointestinal motility disorders in adolescent patients: transitioning to adult care. Gastroenterol Clin North Am 2007;36:749-763, xi.

81. Heredia DJ, Grainger N, McCann CJ, Smith TK. Insights from a novel model of slow-transit constipation generated by partial outlet obstruction in the murine large intestine. Am J Physiol Gastrointest Liver Physiol 2012;303:G1004-G1016.

82. Bampton PA, Dinning PG. High resolution colonic manometry --what have we learnt?--A review of the literature 2012. Curr Gastroenterol Rep 2013;15:328.

83. Dinning PG, Arkwright JW, Gregersen H, o'grady G, Scott SM. Technical advances in monitoring human motility patterns. Neurogastroenterol Motil 2010;22:366-380. 
84. Dinning PG, Wiklendt L, Gibbins I, et al. Low-resolution colonic manometry leads to a gross misinterpretation of the frequency and polarity of propagating sequences: initial results from fiber-optic high-resolution manometry studies. Neurogastroenterol Motil 2013;25:e640-e649.

85. Spencer NJ, Kyloh M, Wattchow DA, et al. Characterization of motor patterns in isolated human colon: are there differences in patients with slow-transit constipation? Am J Physiol Gastrointest Liver Physiol 2012;302:G34-G43.

86. Ragg J, McDonald R, Hompes R, Jones OM, Cunningham C, Lindsey $\mathrm{I}$. Isolated colonic inertia is not usually the cause of chronic constipation. Colorectal Dis 2011;13:1299-1302.

87. Raahave D, Christensen E, Loud FB, Knudsen LL. Correlation of bowel symptoms with colonic transit, length, and faecal load in functional faecal retention. Dan Med Bull 2009;56:83-88.

88. Tomita R, Howard ER. Clinical studies on anorectal myectomy for chronically constipated patients with outlet obstruction in childhood. Hepatogastroenterology 2008;5 5:1600-1605.

89. Piloni V, Tosi P, Vernelli M. MR-defecography in obstructed defecation syndrome (ODS): technique, diagnostic criteria and grading. Tech Coloproctol 2013;17:501-510.

90. Bharucha AE. Update of tests of colon and rectal structure and function. J Clin Gastroenterol 2006;40:96-103.

91. Stanton MP, Hutson JM, Simpson D, et al. Colonic manometry via appendicostomy shows reduced frequency, amplitude, and length of propagating sequences in children with slow-transit constipation. J Pediatr Surg 2005;40:1138-1145.

92. Southwell BR. Colon lengthening slows transit: is this the mechanism underlying redundant colon or slow transit constipation? J Physiol 2010;588(Pt 18):3343.

93. Cong P, Pricolo V, Biancani P, Behar J. Abnormalities of prostaglandins and cyclooxygenase enzymes in female patients with slowtransit constipation. Gastroenterology 2007;133:445-453.

94. Lyster DJ, Bywater RA, Taylor GS. Neurogenic control of myoelectric complexes in mouse isolated colon. Gastroenterology 1995; 108:1371-1378.

95. Fida R, Bywater RA, Lyster DJ, Taylor GS. Chronotropic action of 5-hydroxytryptamine (5-HT) on colonic migrating motor complexes (CMMCs) in the isolated mouse colon. J Auton Nerv Syst 2000;80:52-63

96. Hennig GW, Spencer NJ, Jokela-Willis S, et al. ICC-MY coordinate smooth muscle electrical and mechanical activity in the murine small intestine. Neurogastroenterol Motil 2010;22:e138-e151.

97. Dinning PG, Costa M, Brookes SJ, Spencer NJ. Neurogenic and myogenic motor patterns of rabbit proximal, mid, and distal colon. Am J Physiol Gastrointest Liver Physiol 2012;303:G83-G92.

98. Raghupathi R, Duffield MD, Zelkas L, et al. Identification of unique release kinetics of serotonin from guinea-pig and human enterochromaffin cells. J Physiol 2013;591(Pt 23):5959-5975.

99. McDonnell B, Hamilton R, Fong M, Ward SM, Keef KD. Functional evidence for purinergic inhibitory neuromuscular transmission in the mouse internal anal sphincter. Am J Physiol Gastrointest Liver Physiol 2008;294:G1041-G1051.

100. Costa M, Furness JB. The peristaltic reflex: an analysis of the nerve pathways and their pharmacology. Naunyn Schmiedebergs Arch Pharmacol 1976;294:47-60
101. Smith TK, Oliver GR, Hennig GW, et al. A smooth muscle tone-dependent stretch-activated migrating motor pattern in isolated guinea-pig distal colon. J Physiol 2003;5 51(Pt 3):955-969.

102. Kunze WA, Clerc N, Bertrand PP, Furness JB. Contractile activity in intestinal muscle evokes action potential discharge in guinea-pig myenteric neurons. J Physiol 1999;517(Pt 2):547-561.

103. Spencer NJ, Hennig GW, Dickson E, Smith TK. Synchronization of enteric neuronal firing during the murine colonic MMC. J Physiol 2005;564(Pt 3):829-847.

104. Smith TK, Bornstein JC, Furness JB. Convergence of reflex pathways excited by distension and mechanical stimulation of the mucosa onto the same myenteric neurons of the guinea pig small intestine. J Neurosci 1992;12:1502-1510.

105. Broadhead MJ, Bayguinov PO, Okamoto T, Heredia DJ, Smith TK. $\mathrm{Ca}^{2+}$ transients in myenteric glial cells during the colonic migrating motor complex in the isolated murine large intestine. J Physiol 2012;590(Pt 2):335-350.

106. Thomas EA, Sjövall H, Bornstein JC. Computational model of the migrating motor complex of the small intestine. Am J Physiol Gastrointest Liver Physiol 2004;286:G564-G572.

107. Schemann M, Michel K, Peters S, Bischoff SC, Neunlist M. Cutting-edge technology. III. Imaging and the gastrointestinal tract: mapping the human enteric nervous system. Am J Physiol Gastrointest Liver Physiol 2002;282:G919-G925.

108. Yamato S, Spechler SJ, Goyal RK. Role of nitric oxide in esophageal peristalsis in the opossum. Gastroenterology 1992;103:197-204.

109. Shuttleworth CW, Xue C, Ward SM, de Vente J, Sanders KM. Immunohistochemical localization of $3^{\prime}, 5^{\prime}$-cyclic guanosine monophosphate in the canine proximal colon: responses to nitric oxide and electrical stimulation of enteric inhibitory neurons. Neuroscience 1993;56:513-522.

110. Hwang SJ, Blair PJ, Durnin L, Mutafova-Yambolieva V, Sanders KM, Ward SM. P2Y1 purinoreceptors are fundamental to inhibitory motor control of murine colonic excitability and transit. J Physiol 2012;590(Pt 8):1957-1972.

111. Blair PJ, Bayguinov Y, Sanders KM, Ward SM. Relationship between enteric neurons and interstitial cells in the primate gastrointestinal tract. Neurogastroenterol Motil 2012;24:e437-e449.

112. Spencer NJ, Bywater RA, Holman ME, Taylor GS. Spontaneous and evoked inhibitory junction potentials in the circular muscle layer of mouse colon. J Auton Nerv Syst 1998;69:115-121.

113. Spencer NJ, Bywater RA, Taylor GS. Disinhibition during myoelectric complexes in the mouse colon. J Auton Nerv Syst 1998;71: 37-47.

114. Brierley SM, Nichols K, Grasby DJ, Waterman SA. Neural mechanisms underlying migrating motor complex formation in mouse isolated colon. Br J Pharmacol 2001;132:507-517.

115. Lee HT, Hennig GW, Park KJ, et al. Heterogeneities in ICC Ca ${ }^{2+}$ activity within canine large intestine. Gastroenterology 2009;136: 2226-2236.

116. Smith TK, Reed JB, Sanders KM. Electrical pacemakers of canine proximal colon are functionally innervated by inhibitory motor neurons. Am J Physiol 1989;256(3 Pt 1):C466-C477.

117. Smith TK, Reed JB, Sanders KM. Origin and propagation of electrical slow waves in circular muscle of canine proximal colon. Am J Physiol 1987;252(2 Pt 1):C215-C224. 
118. Smith TK, Reed JB, Sanders KM. Interaction of two electrical pacemakers in muscularis of canine proximal colon. Am J Physiol 1987;252(3 Pt 1):C290-C299.

119. Yoneda S, Takano H, Takaki M, Suzuki H. Properties of spontaneously active cells distributed in the submucosal layer of mouse proximal colon. J Physiol 2002;542(Pt 3):887-897.

120. Lee HT, Hennig GW, Fleming NW, et al. The mechanism and spread of pacemaker activity through myenteric interstitial cells of Cajal in human small intestine. Gastroenterology 2007;132:18521865.

121. Spencer NJ, Smith TK. Simultaneous intracellular recordings from longitudinal and circular muscle during the peristaltic reflex in guinea-pig distal colon. J Physiol 2001;533(Pt 3):787-799.

122. Smith TK, Furness JB. Reflex changes in circular muscle activity elicited by stroking the mucosa: an electrophysiological analysis in the isolated guinea-pig ileum. J Auton Nerv Syst 1988;25:205-218.

123. Spencer NJ, Smith TK. Mechanosensory S-neurons rather than AH-neurons appear to generate a rhythmic motor pattern in guinea-pig distal colon. J Physiol 2004;558(Pt 2):577-596.

124. Smith TK, Bornstein JC, Furness JB. Interactions between reflexes evoked by distension and mucosal stimulation: electrophysiological studies of guinea-pig ileum. J Auton Nerv Syst 1991;34:69-75.

125. Spencer NJ, Dickson EJ, Hennig GW, Smith TK. Sensory elements within the circular muscle are essential for mechanotransduction of ongoing peristaltic reflex activity in guinea-pig distal colon. J Physiol 2006;576(Pt 2):519-531.

126. Smith TK, McCarron SL. Nitric oxide modulates cholinergic reflex pathways to the longitudinal and circular muscle in the isolated guinea-pig distal colon. J Physiol 1998;512(Pt 3):893-906.

127. Smith TK, Robertson WJ. Synchronous movements of the longitudinal and circular muscle during peristalsis in the isolated guinea-pig distal colon. J Physiol 1998;506(Pt 2):563-577.

128. Bayliss WM, Starling EH. The movements and innervation of the small intestine. J Physiol 1901;26:125-138.

129. Frigo GM, Lecchini S. An improved method for studying the peristaltic reflex in the isolated colon. Br J Pharmacol 1970;39:346-356.

130. Kunze WA, Bertrand PP, Furness JB, Bornstein JC. Influence of the mucosa on the excitability of myenteric neurons. Neuroscience 1997;76:619-634.

131. Racké K, Reimann A, Schwörer H, Kilbinger H. Regulation of 5-HT release from enterochromaffin cells. Behav Brain Res 1996; 73:83-87.

132. Wood JD, Mayer CJ. Serotonergic activation of tonic-type enteric neurons in guinea pig small bowel. J Neurophysiol 1979;42:582-593.

133. Pan H, Galligan JJ. 5- $\mathrm{HT}_{1 \mathrm{~A}}$ and $5-\mathrm{HT}_{4}$ receptors mediate inhibition and facilitation of fast synaptic transmission in enteric neurons. Am J Physiol 1994;266(2 Pt 1):G230-G238.

134. Monro RL, Bertrand PP, Bornstein JC. ATP and 5-HT are the principal neurotransmitters in the descending excitatory reflex pathway of the guinea-pig ileum. Neurogastroenterol Motil 2002;14: 255-264.

135. Galligan JJ. Electrophysiological studies of 5-hydroxytryptamine receptors on enteric neurons. Behav Brain Res 1996;73:199-201.

136. Fiorica-Howells E, Maroteaux L, Gershon MD. Serotonin and the $5-\mathrm{HT}_{2 \mathrm{~B}}$ receptor in the development of enteric neurons. J Neurosci 2000;20:294-305.
137. Borman RA, Tilford NS, Harmer DW, et al. 5- $\mathrm{HT}_{2 \mathrm{~B}}$ receptors play a key role in mediating the excitatory effects of $5-\mathrm{HT}$ in human colon in vitro. Br J Pharmacol 2002;135:1144-1151.

138. Bassil AK, Taylor CM, Bolton VJ, et al. Inhibition of colonic motility and defecation by RS-127445 suggests an involvement of the $5-\mathrm{HT}_{2 \mathrm{~B}}$ receptor in rodent large bowel physiology. $\mathrm{Br} \mathrm{J}$ Pharmacol 2009; $158: 252-258$.

139. Spencer NJ, Nicholas SJ, Sia TC, Staikopoulos V, Kyloh M, Beckett EA. By what mechanism does ondansetron inhibit colonic migrating motor complexes: does it require endogenous serotonin in the gut wall? Neurogastroenterol Motil 2013;25:677-685.

140. Zafirov DH, Palmer JM, Nemeth PR, Wood JD. Cyclic 3',5'-adenosine monophosphate mimics slow synaptic excitation in myenteric plexus neurons. Brain Res 1985;347:368-371.

141. Neal KB, Bornstein JC. Serotonergic receptors in therapeutic approaches to gastrointestinal disorders. Curr Opin Pharmacol 2006; 6:547-552.

142. Stevens RJ, Publicover NG, Smith TK. Induction and organization of $\mathrm{Ca}^{2+}$ waves by enteric neural reflexes. Nature 1999;399:62-66.

143. Zagorodnyuk VP, Spencer NJ. Localization of the sensory neurons and mechanoreceptors required for stretch-evoked colonic migrating motor complexes in mouse colon. Front Physiol 2011;2:98.

144. Spencer NJ, Nicholas SJ, Robinson L, et al. Mechanisms underlying distension-evoked peristalsis in guinea pig distal colon: is there a role for enterochromaffin cells? Am J Physiol Gastrointest Liver Physiol 2011;301:G519-G527.

145. Keating DJ, Spencer NJ. Release of 5-hydroxytryptamine from the mucosa is not required for the generation or propagation of colonic migrating motor complexes. Gastroenterology 2010;138:659-670, e1-e2.

146. Smith TK, Dickson EJ, Heredia DJ, Hennig GW, Bayguinov PO. Controversies involving the role of 5 -hydroxytryptamine in generating colonic migrating motor complexes: what is spontaneous? Gastroenterology 2010;138:1213-1214.

147. Barnes KJ, Beckett EA, Brookes SJ, Sia TC, Spencer NJ. Control of intrinsic pacemaker frequency and velocity of colonic migrating motor complexes in mouse. Front Neurosci 2014;8:96.

148. Bulbring E, Crema A. The action of 5-hydroxytryptamine, 5-hydroxytryptophan and reserpine on intestinal peristalsis in anaesthetized guinea-pigs. J Physiol 1959;146:29-53.

149. Sia TC, Flack N, Robinson L, et al. Is serotonin in enteric nerves required for distension-evoked peristalsis and propulsion of content in guinea-pig distal colon? Neuroscience 2013;240:325-335.

150. Kuhn DM, Wolf WA, Youdim MB. 5-Hydroxytryptamine release in vivo from a cytoplasmic pool: studies on the 5 -HT behavioural syndrome in reserpinized rats. Br J Pharmacol 1985;84:121-129.

151. Alabi AA, Tsien RW. Synaptic vesicle pools and dynamics. Cold Spring Harb Perspect Biol 2012;4:a013680

152. Florin SM, Kuczenski R, Segal DS. Effects of reserpine on extracellular caudate dopamine and hippocampus norepinephrine responses to amphetamine and cocaine: mechanistic and behavioral considerations. J Pharmacol Exp Ther 1995;274:231-241.

153. Yavich L, MacDonald E. Dopamine release from pharmacologically distinct storage pools in rat striatum following stimulation at frequency of neuronal bursting. Brain Res 2000;870:73-79.

154. Zariwala HA, Borghuis BG, Hoogland TM, et al. A Cre-depend- 
ent GCaMP3 reporter mouse for neuronal imaging in vivo. J Neurosci 2012;32:3131-3141.

155. Akerboom J, Chen TW, Wardill TJ, et al. Optimization of a GCaMP calcium indicator for neural activity imaging. J Neurosci 2012;32:13819-13840.
156. Nagel G, Brauner M, Liewald JF, Adeishvili N, Bamberg E, Gottschalk A. Light activation of channelrhodopsin-2 in excitable cells of Caenorhabditis elegans triggers rapid behavioral responses. Curr Biol 2005;15:2279-2284. 